\title{
An Experimental Study on the Effect of Micro- Metakaolin on the Strength and Swelling Characteristics of Expansive Soils
}

\section{Mohamed Sakr}

Tanta University Faculty of Engineering

Waseim Azzam

Tanta University Faculty of Engineering

Mohamed Meguid

McGill University Faculty of Engineering

Hebatalla Ghoneim ( $\nabla$ hebatalla_ghoneim@f-eng.tanta.edu.eg )

Tanta University Faculty of Engineering https://orcid.org/0000-0003-2840-2821

\section{Research Article}

Keywords: ground improvement, expansive soil, micro-metakaolin, free swell index

Posted Date: January 3rd, 2022

DOI: https://doi.org/10.21203/rs.3.rs-544440/v1

License: (a) (i) This work is licensed under a Creative Commons Attribution 4.0 International License. Read Full License 


\section{Abstract}

Expansive soils are found in many parts of the world, especially in arid areas and dry weather regions. Urbanization and development of new cities around the world resulted in construction in areas of challenging subsurface soil conditions. For example, in the Middle East, the Government of Egypt is building several new cities to accommodate the continuous increase in the country's population. Most of these new cities are located in areas underlain by expansive soils. In this study, a series of laboratory tests were carried out to investigate the effect of introducing micro-metakaolin into the matrix of an expansive soil to improve the swelling potential as a new stabilizing material. Test results showed that micro-metakaolin can considerably decrease the free swell index of the soil by $37 \%$ and $54 \%$ at micrometakaolin content of $15 \%$ and $25 \%$, respectively. In addition, the shear strength of the soil was found to also increase as a result of the introduction of the micro-metakaolin material. Adding $25 \%$ micrometakaolin content reduced the swelling pressure of the soil by about $33 \%$. The results suggest that the proposed method is efficient in stabilizing and improving the properties of expansive soils found in arid areas. This is important to control excessive swelling and prevent possible damage to the supported structures.

\section{Introduction}

The term "expansive soils" is commonly used as generic description of all soils containing smectite mineral. This soil type is prone to volumetric changes due to changes in moisture content. The main cause of volume change is essentially the increase or decrease in soil moisture content, which results in the swelling or shrinkage phenomena, respectively. Other factors affecting soil volume change include soil structure, particle interactions (mineralogy), stress history and specific surface. Expansive soil deposits can be found in many areas especially in semi-arid regions located in tropical and temperate climate zones worldwide. This explains the reasons engineers in these areas rely on soil stabilization techniques to improve the geotechnical characteristics of expansive soils to control foundation settlement and prevent possible failure (Forouzan, 2016).

The behavior of modified expansive soil using lime was studied (Thanappan et al., 2020). The grain surface of the swelling clay that interacts with water was improved by utilizing nanocomposite as a hydrophobic material reducing the montmorillonite activity and increasing the net electrical attraction between adjacent particles (Azzam, 2012). The engineering properties of expansive soil when mixed with fly ash was studied (Kate, 2008). Gupta and Sharma (2014) investigated the effect of adding micro silica fume on the shear strength of expansive soil used as subgrade material for construction of flexible pavements in rural roads with low traffic volume. Elmashad (2017) performed an experimental investigation was performed to quantify the effect of mixing bentonite as an expansive soil with chemical additives such as sodium chloride, lime, sodium carbonate and ammonium chloride. Also, the effect of polyvinyl alcohol and potassium carbonate on improving the expansive soil was discussed (Zhang et al., 2019) 
A review of the emerging trends in expansive soil stabilization such as chemical techniques and solid wastes was studied by Ikeagwuani and Nwonu (2019). The effect of using egg shell powder mixed with plastic wastes (Alzaidy, 2019) and with corn cob ash (Sankar et al., 2019) to stabilize the expansive soil was examined. Chemical analysis of expansive soils using X-Ray diffraction (XRD) and Scanning Electron Microscope (SEM) were conducted to evaluate the geotechnical properties of expansive soil before and after the stabilization using tire rubber powder (TRP) and cement kiln dust (CKD) (Naseem et al., 2019). Several researchers reported improvement in the geotechnical properties of expansive soils using different additives such as coconut husk ash (Jagwani and Jaiswal, 2019), lime mixed with volcanic ash (Cheng and Huang, 2018), dust shield polymer (Ahmed and Kamel, 2013), waterborne polymer (Naeini et al., 2012), cement dust (Alzubaidi et al., 2016), Pumice mixed with lime (Mesfun et al., 2019), rice husk ash (Husain et al., 2014) and nanoclay material (Sakr et al., 2021).

In this study an alternative technique to improve the characteristics of expansive soil is developed using micro-metakaolin as a new stabilizing agent. Researchers (Nagar and Abu zeid, 2018; Zeedan and El Shimy, 2012; Hassan, 2016; Abdel Gawwad et al., 2017; Morsy, 2015) investigated the use of metakaolin as an eco-friendly binder that can be used as a substitute for the calcium silicate hydrate which is an essential component of Portland cement. Although, metakaolin is widely used in concrete mixes, investigations related to its use in soil improvement is very scarce in the literature. The effect of micrometakaolin on some of the geotechnical soil properties was studied by different investigators (Sakr et al., 2020; Bayang et al., 2017). This research aims to investigate the effect of micro-metakaolin content on the geotechnical behavior of bentonite-based soil. The effect of this technique on controlling the swelling potential of the tested expansive soil samples is presented and discussed.

\section{Experimental Work \\ 2.1. Soil used}

The soil used in this study was obtained from the "Bentonite and Derivatives Company" located in Borg Al-Arab, Alexandria, Egypt. The bentonite is used here to represent the expansive soil in a homogeneous phase. The main properties of the used bentonite are summarized in Tables 1 and 2. The material has a liquid limit of about $330 \%$ and plastic limit of $36 \%$. The free swell index (ASTM D4546-08) of about $502 \%$ and plasticity index of $295 \%$. These values are consistent with those reported by other researchers for various bentonite products (e.g. Elmashad, 2017). The results of the hydrometer analysis performed on the bentonite material indicate that the tested samples contains $64 \%$ clay and $36 \%$ silt. 
Table 1

Properties of the used bentonite material

\begin{tabular}{|ll|}
\hline Property & Value \\
\hline Free swell index, SI (\%) & 502 \\
\hline Unit weight, Y $\left(\mathrm{kN} / \mathrm{m}^{3}\right)$ & 10.7 \\
\hline Liquid limit, L.L (\%) & 331 \\
\hline Plastic limit, P.L (\%) & 36 \\
\hline Plasticity index, P.I (\%) & 295 \\
\hline Specific gravity, $\mathrm{G}_{\mathrm{S}}$ & 2.6 \\
\hline Initial average water content, $\mathrm{W}_{\mathrm{c}}(\%)$ & 10 \\
\hline
\end{tabular}

Table 2

Mineralogical and chemical properties of the used bentonite (according to the manufacturer's data sheet)

\section{Mineralogical properties:}

\begin{tabular}{ll}
\hline Quartz (\%) & 37 \\
\hline Montmorillonite (\%) & 43 \\
\hline Kaolinite (\%) & 15 \\
\hline Others (\%) & 5 \\
\hline Chemical properties: & \\
\hline $\mathrm{SiO}_{2}(\%)$ & 61 \\
\hline $\mathrm{Al}_{2} \mathrm{O}_{3}(\%)$ & 14.59 \\
\hline $\mathrm{Fe}_{2} \mathrm{O}_{3}(\%)$ & 2.09 \\
\hline $\mathrm{TiO}_{2}, \mathrm{SO}$ & $2 \mathrm{Cl}, \mathrm{BaO}(\%)$ \\
\hline $\mathrm{CaO}_{2} \mathrm{~K}_{2} \mathrm{O}(\%)$ & $<0.5$ \\
\hline $\mathrm{MgO}, \mathrm{Na}_{2} \mathrm{O}(\%)$ & 0.77 \\
\hline Loss on ignition, LOI (\%) & 13.20 \\
\hline
\end{tabular}

\subsection{Micro-metakaolin $\left(M_{m}\right)$}


In this study, the used additive for treating the expansive soil is a commercial material known as micrometakaolin $\left(M_{m}\right)$ obtained from the "Aluminum Sulphate Company of Egypt" located in Kaliobeya province, Egypt. The properties of the used $M_{m}$ are summarized in Tables 3 and 4 . The liquid and plastic limits of the material is found to be $65 \%$ and $35 \%$, respectively with unit weight of about $11.2 \mathrm{kN} / \mathrm{m}^{3}$.

Table 3

Properties of the used micrometakaolin addiditive

\begin{tabular}{|ll|}
\hline Property & Value \\
\hline Free swell index, SI (\%) & 0.0 \\
\hline Unit weight, Y $\left(\mathrm{kN} / \mathrm{m}^{3}\right)$ & 11.2 \\
\hline Liquid limit, L.L. (\%) & 65 \\
\hline Plastic limit, P.L. (\%) & 35 \\
\hline Plasticity index, P.I. (\%) & 30 \\
\hline
\end{tabular}

Table 4

Mineralogical and chemical properties of the used micro-metakaolin (according to the manufacturer's data sheet)

\begin{tabular}{|ll|}
\hline Mineralogical properties: & \\
\hline Appearance & Creamy, buff fine powder $(20-40 \mu \mathrm{m})$ \\
\hline Moisture (\%) & $<1.0$ \\
\hline $\mathrm{pH}(10 \%$ solids) & 7.0 \\
\hline Specific gravity & 2.65 \\
\hline Chemical Properties: & \\
\hline $\mathrm{SiO}_{2}(\%)$ & 56 \\
\hline $\mathrm{Al}_{2} \mathrm{O}_{3}(\%)$ & 35 \\
\hline $\mathrm{Fe}_{2} \mathrm{O}_{3}(\%)$ & 1.0 \\
\hline $\mathrm{TiO}_{2}(\%)$ & 2.3 \\
\hline $\left.\mathrm{CaO}^{2} \%\right)$ & 0.09 \\
\hline $\left.\mathrm{MgO}^{2} \%\right)$ & 0.04 \\
\hline $\mathrm{Na}_{2} \mathrm{O}(\%)$ & 0.10 \\
\hline $\mathrm{LOSS}^{2}$ on ignition, LOI (\%) & 1.0 \\
\hline
\end{tabular}


Metakaolin is highly reactive metastable clay. It is defined as "an anhydrous aluminosilicate obtained from calcining kaolinite at $750^{\circ} \mathrm{C}$ for two hours". It is used in geopolymeric systems and in mineral admixture as a primary aluminum silicate source (Zeedan and El Shimy, 2012).

\subsection{X-Ray Diffraction analysis}

X-Ray diffraction (XRD) tests were conducted on both the bentonite as well as the $M_{m}$ material at the central laboratory at Tanta University, Egypt. This is important to study the crystal structure and understand the chemical composition of each material.

\subsubsection{XRD analysis of the bentonite material}

The measured 2Theta chart for the bentonite in the wet state is shown in Fig. 1a. XRD tests were also conducted on dry and oven dried bentonite samples as indicative (benchmark) tests and the results are shown in Figs. $1 \mathrm{~b} \& 1 \mathrm{c}$ respectively. Kaolinite component $(K)$ peaks mainly exist at 2 Theta of $12.3^{\circ}$ and $24.9^{\circ}$; quartz component $(Q)$ peaks exist at 2 Theta of about $27^{\circ}$; and smectite (montmorillonite) component peaks exist at 2 Theta equals $5.9^{\circ}$. As a result, a tangent was drawn, to calculate the areas under those peaks. Using the calculated areas, the percentage of each component can be obtained. The soil mineralogy is summarized in Table 5 and shows that the bentonite material consists mainly of $40 \%$ quartz and $40 \%$ smectite with about $16 \%$ kaolinite. XRD pattern indicates the presence of quartz, smectite and kaolinite peaks at its characteristic 2 Theta values.

Table 5

Mineralogy of the expansive soil

\begin{tabular}{|llll|}
\hline Kaolinite & Quartz & Smectite & Others \\
\hline $16 \%$ & $40 \%$ & $40 \%$ & $4 \%$ \\
\hline
\end{tabular}

As shown in Figs. 1a, 1b \& 1c, the smectite peaks are higher for bentonite in the wet state as compared to the dry and the oven dried states. This could be attributed to the fact that smectite particles have high affinity to water and will adsorb the added water leading to increase in the size of smectite particles. This in turn leads to an increase in the height of the mineral's XRD peaks.

\subsubsection{XRD analysis of the micro-metakaolin $\left(M_{m}\right)$ material}

X-Ray diffraction (XRD) analysis was conducted on the $M_{m}$ sample in the dry and oven dried states. It was found that the 2 Theta chart for the $M_{m}$ in the dry and oven dried states are nearly identical. The 2Theta chart for the $M_{m}$ in the dry state is shown in Fig. $1 \mathrm{~d}$. This 2 Theta chart shows the presence of quartz and kaolinite. The smectite does not appear in the sample.

\subsection{SEM results for the used bentonite (expansive soil)}

A Scanning Electron Microscope (SEM) is performed on a bentonite sample. The sample was scanned at five different resolutions with magnification factors of $75 \cdot, 150 \cdot, 200 \cdot, 350 \cdot$ and $500 \cdot$, to allow for better 
understanding of the material composition. The SEM images of the tested samples are shown in Fig. 2a $\& 2 b$ at two resolutions with magnification factors of $200 \cdot$ and 350 . SEM images revealed that the soil contains agglomerated particles of average sizes of nearly $1.2 \mu \mathrm{m}$. The heterogeneous and non-smooth nature of particles reflects its high surface area and ability to absorb water, which is usually accompanied by high swelling activity.

\subsection{TEM results for the used bentonite (expansive soil)}

A Transmission Electron Microscope (TEM) has been conducted on the bentonite sample and the results are shown in Figs. 2c \& 2d. The samples were scanned at two resolutions for more accuracy and better understanding of the composition. These resolutions correspond to magnification factors of 20000 . and 40000. TEM images confirmed that the size of the soil particles is more than $100 \mathrm{~nm}$. In addition, the non-smooth nature of particles can be clearly observed.

\subsection{Preparation of the bentonite - micro-metakaolin mixture}

Preparing the bentonite- $M_{m}$ mixture is an important step in the experiments to ensure a homogeneous soil mixture. The main principle is to prepare soil with a certain percentage of $M_{m}$ content, and then compact the mixture to a target dry unit weight directly in the Oedometer cell or in the direct shear box using a certain energy. This approach was recommended by Benkadja and Belouahri (2010). The standard compaction tool used to prepare the tested soil samples is shown in Fig. 3a \& 3b, which is also used by other investigators (Sakr et al., 2014; Ayadat and Belouahri, 1996; Rabah, 2014). It consists of a disc fixed to a rod with a load of $136 \mathrm{gm}$ that slides along the rod. The load falls from $150 \mathrm{~mm}$ height under gravity and strikes the disc to compact the tested soil. In this study, we used an energy of compaction (Ec) equals $8 \mathrm{~J}$ or 20 blows/layer matching values verified by Benkadja and Belouahri (2010). This compaction energy gives a maximum dry density of $75-80 \%$ of maximum $Y_{d r y}$ which is consistent with the results given by Rabah (2014) and Nazir (2012).

To prepare the soil samples with $M_{m}$ additive, the following steps are consistently followed: (1) the samples were oven dried at $105^{\circ} \mathrm{C}$ (Elmashad, 2017), weighted according to the dry unit weight of the soil and the chosen percentage of $M_{m}$; (2) mixing is performed for a period of 10 minutes; (3) the mixture is compacted using the tool described above in two layers with the same energy (20 blows/layer); (4) when the target level is reached, the tested sample is levelled inside the test apparatus.

\section{Experimental Program}

Although this study focuses on the swell potential mitigation of expansive soil, other geotechnical characteristics of the treated soil were also investigated. In particular, the effect of adding different percentages of $M_{m}$ on Atterberg limits, free swell index, swelling pressure, compaction and direct shear strength of treated expansive soil is experimentally investigated. In total, fifty-seven tests were performed on the expansive soil before and after treatment using different percentages of micro-metakaolin. 
The micro-metakaolin was added to the soil samples as a percentage of the dry soil mass, namely $5 \%$, $10 \%, 15 \%, 20 \%$ and $25 \%$ and the mixing process continued for 10 minutes for each added $M_{m}$ portion (Sakr et al., 2020; Bayang et al., 2017). After the mixing is completed, consistency limit tests were performed on the bentonite soil only (control samples) without treatment and on the soil mixed with $M_{m}$ (treated samples) according to the ASTM D4318-10. Samples were remolded at different moisture contents and dry densities were determined using the modified Proctor test apparatus according to the ASTM D1557. A summary of the performed tests is provided in Table 6.

To investigate the relationship between the swelling characteristics and the percentage of micrometakaolin added, the relationship between the swelling pressures and the time elapsed since water addition to the prepared mix was studied. The elapsed time that corresponds to insignificant change in swelling pressure is recorded. Figure 4 shows that the swelling pressure consistently increases for the case of expansive soil without additives throughout the first week. After 8 days, the change in swelling pressure is found to be almost negligible as the rate of swelling pressure remains approximately constant. Therefore, the test duration for the rest of the tests was set at 8 days. This is consistent with the results reported by Elmashad (2017) and Komine \& Ogata (1994).

To investigate the swelling activity of the expansive soil, free swell index tests were performed according to ASTM D4546-08. The soil samples were oven dried at $105^{\circ} \mathrm{C}$ and $30 \mathrm{~m} /$ of water were placed in a 100 $\mathrm{m} /$ graduated cylinder. Pre-sieved soil was progressively added to the water in $1 \mathrm{gm}$ increments. After the $10 \mathrm{gm}$ were added, water was poured to fill the cylinder up to $100 \mathrm{~m} /$ and to rinse any unmixed particle. The final volume of the expansive soil was measured after reaching the full expanded volume. The free swell index is calculated as:

$$
\mathrm{SI}=\frac{v_{f}-V_{i}}{v_{i}} \times 100
$$

Where: $S /$ is the free swell index (\%), $V_{f}$ is the final volume $\left(\mathrm{cm}^{3}\right)$ and $V_{i}$ is the initial volume $\left(\mathrm{cm}^{3}\right)$. Swelling tests were then performed in a standard one-dimensional Oedometer apparatus (ECP 202-part 5). The oven dried soil samples as described earlier in a fixed stainless steel Oedometer ring with $50 \mathrm{~mm}$ in internal diameter and $20 \mathrm{~mm}$ in height. Three samples were tested under vertical pressures of 100 $\mathrm{kN} / \mathrm{m}^{2}, 200 \mathrm{kN} / \mathrm{m}^{2}$ and $300 \mathrm{kN} / \mathrm{m}^{2}$. Each pressure increment was applied to the dry sample and sustained until the vertical movement has stopped. Water was then added to the cell and the swelling of the sample was recorded with time (Elmashad, 2017). The results of the final swelling ratio under each pressure increment are discussed in the next section. The swelling ratio is expressed as the percentage of the total swell to the initial sample's height.

$$
S R=\frac{H_{f}-H_{i}}{H_{i}} \times 100
$$

Where: $S R=$ swelling ratio $(\%) \mathrm{H}_{1}=$ final height $(\mathrm{cm})$ and $\mathrm{H}_{1}=$ initial height $(\mathrm{cm})$. 
For the direct shear test, the oven dried soil samples were compacted in a shear box with internal dimensions of $60 \times 60 \mathrm{~mm}^{2}$ and a height of $25 \mathrm{~mm}$. Three samples were tested for each $M_{m}$ percentage under stress increments of $25 \mathrm{kN} / \mathrm{m}^{2}, 50 \mathrm{kN} / \mathrm{m}^{2}$ and $100 \mathrm{kN} / \mathrm{m}^{2}$ with a rate of shear displacement of $0.0005 \mathrm{~mm} / \mathrm{min}$. This slow rate was chosen to allow for pore pressure dissipation for tests involving soaked samples as per ASTM D3080-11. The chosen loading rate is consistent with that reported by Sinha (1998). Each stress increment was applied to the dry sample and the corresponding shear strength was recorded when the horizontal displacement reaches $0.15 \%$ of the sample's side length (ECP 202-part 2). Similar procedure was adopted for each prepared sample such that the oven dried sample is compacted as described above and the next stress increment was applied. Also, additional tests were conducted on the bentonite material alone and on the bentonite treated with $M_{m}$ in the soaked state according to ASTM D3080-11. The components of the shear strength were determined in both the unsoaked and soaked states.

\section{Results And Discussion}

\subsection{X-Ray Diffraction}

The XRD results (2Theta charts) for the untreated soil is presented in Figures $1 \mathrm{a}, 1 \mathrm{~b} \& 1 \mathrm{c}$. While, Figure 5 shows the XRD results (2Theta chart) for the treated soil using $25 \% M_{m}$ based on the dry weight of the sample. The XRD images for the treated soil indicate that the mineralogical characteristics of the treated soil did not significantly change with the increase in $M_{m}$ content up to $25 \%$. This attributed to the fact that the $M_{m}$ material used in this study is essentially insoluble and does not react to the presence of the soil material by just mixing with water. The micro-metakaolin seems to have filled the voids in the soil matrix leading to water adsorption and a strong bond develops between the soil minerals and the micrometakaolin. This is consistent with the results reported by Taha and Taha (2012).

\subsection{Scanning Electron Microscope (SEM) and Transmission Electron Microscope (TEM) Results}

A series of Scanning Electron Microscope (SEM) tests has been performed on the soil samples treated with $M_{m}$ at percentages of $10 \%$ and $25 \%$. Each sample was scanned at five resolutions that correspond to magnifications of $75^{\prime}, 150^{\prime}, 200^{\prime}, 350^{\prime}$ and $500^{\prime}$. The SEM images of the treated expansive soil with $M_{m}$ are shown in Figure 6. The SEM image of the untreated soil sample provides the benchmark for orientation and arrangement of the expansive soil structure. The spatial distribution of the solid particles and the particle-to-particle relationship was analyzed. In addition, aggregation and the inter-connected voids in the soil matrices were examined. It is found that the addition of $M_{m}$ to the expansive soil modifies the microstructure fabrics resulting in the formation of a new material. These tests confirmed the presence of $M_{m}$ within the intra particle voids. The new matrix is found to resemble gel-like structure with irregularly arranged particles. The additive also increases the soil density due to the filling of the pores. This stabilization technique increases the net electrical attraction between adjacent particles. The 
voids are found to decrease and become filled with interconnected material leading to increasing the adhesion and improving the expansive characteristics of the treated soil.

Transmission Electron Microscope (TEM) tests have been performed on expansive soil samples treated with $M_{m}$ at percentages of $10 \%$ and $25 \%$. Each sample was scanned tho different resolutions that correspond to magnification factors of 20000' and 40000'. The TEM images for the treated expansive soil with $M_{m}$ are shown in Figure 7. The TEM analysis confirmed the effectiveness of the $M_{m}$ additive in constructing a new material resulting from the interaction between the expansive soil and the micrometakaolin. The addition of $M_{m}$ at $10 \%$ and $25 \%$ is found to clearly enhance the TEM micrograph.

\subsection{The effect of the micro-metakaolin on the consistency of the expansive soil}

Figure 8 presents the effect of treating the bentonite soil with $M_{m}$ additive on the soil consistency. It is clear that micro-metakaolin has a significant effect on the consistency indices of the expansive soil, since it reduces the soil liquid limit and increases its plastic limit with the increase in $M_{m}$ content. This behavior is attributed to the nature of the added micro-metakaolin, which affects the interaction between the soil particles. Adding $M_{m}$ is found to change the properties of the treated soil from being highly plastic to a relatively low plastic due to the decrease in liquid limit and the increase in plastic limit. As illustrated in Figure 8 , the plasticity index has notably decreased by about $43 \%$ after treatment.

\subsection{The effect of adding micro-metakaolin on the compaction parameters of the expansive soil}

The compaction curves obtained for the mixes of different plasticity values treated using different percentages of $M_{m}$ are shown in Figure 9 . As can be seen from the figure, increasing the $M_{m}$ content up to $15 \%$ results in a slight increase in the maximum dry unit weight of about $7 \%$ associated with a decrease in the optimum moisture content of the treated soil to a value similar to that of the untreated soil. Beyond the $15 \% M_{m}$ content, the maximum dry unit weight started to gradually decrease accompanied by an increase in the optimum moisture content.

The increase in the maximum dry unit weight of the soil treated with $M_{m}$ of up to $15 \%$ can be explained by the fact that the weight of the treated samples generally increase as the void ratio of the mixture decrease. During the initial chemical reaction, $M_{m}$ particles within the mixture absorb the excess water and thus prevent additional water molecules from entering the voids. Adding more micro-metakaolin above $15 \%$, the maximum dry unit weight of the mixture is found to decrease. This can be attributed to the fact that increasing $M_{m}$ content beyond an optimum value can cause agglomeration of the additive particles, which in turn can cause an increase in void ratio resulting in a decrease in the unit weight and an increase in the optimum water content of the treated soil.

\subsection{The effect of micro-metakaolin on the swelling properties of the expansive soil}

\subsubsection{Free swell tests}


Free swell index tests were performed on the treated soil using different $M_{m}$ percentages. As illustrated in Table 7 , at $15 \%$ and $25 \% M_{m}$ content, the free swell index decreased by about $37 \%$ and $54 \%$, respectively as compared to the untreated sample. Considering the economic advantage of the treatment process, an optimum content for $M_{m}$ should not be more than $25 \%$. In spite of that, increasing the $M_{m}$ content reduces the free swell index of soil. This behavior can be attributed to the fact that the micro-metakaolin absorbs the excess water entering the soil matrix leading to a modified material structure with less swelling ability with voids that are much smaller in size. It can be concluded that $M_{m}$ has a great effect on reducing the swell potential of bentonite soils.

\subsubsection{Swelling pressure:}

In this study, the swelling pressure was evaluated using a standard one-dimensional Oedometer apparatus (ECP 202-part 5). Three samples were tested for each micro-metakaolin content under applied pressures of 100, 200 and $300 \mathrm{kN} / \mathrm{m}^{2}$ as shown in Figure 10. The figure presents a relationship between the swelling ratios for different percentages of micro-metakaolin and different applied loads. The final swelling for each case was recorded with time and the swelling pressure for each $M_{m}$ percentage is plotted in Figure 11a. It is observed that the swelling pressure decreases as the $M_{m}$ content increases and the relationship is approximately linear and can be expressed by:

$\mathrm{Sp}=-5.6\left(M_{m}\right.$ content $\left.\%\right)+410$

Where; $S_{p}$ is the swelling pressure in $\mathrm{kN} / \mathrm{m}^{2}$ and $M_{m}$ is the percent of the added micro-metakaolin.

Swelling pressure reduction $\left(S p_{r}\right)$ can be defined as the ratio between the rate of decrease in the swelling pressure due to the addition of $M_{m}$ and the swelling pressure for the untreated soil. This relationship can be expressed as:

$\mathrm{Sp}_{\mathrm{r}}(\%)=\frac{[\mathrm{Sp} \text { (untreated) }-\mathrm{Sp}(\text { treated })]}{\mathrm{Sp} \text { (untreated) }}$

Figure $11 \mathrm{~b}$ depicts the change in swelling pressure reduction $\left(\mathrm{Sp}_{\mathrm{r}}\right)$ for different $M_{m}$ percentages. The relationship can be expressed as:

$$
\mathrm{Sp}_{\mathrm{r}}(\%)=1.3659\left(M_{m} \text { content } \%\right)
$$

For $M_{m}$ of $15 \%$ and $25 \%$, the swelling pressure decreased by about $22 \%$ and $33 \%$, respectively, as compared to the untreated sample. The optimum percentage of $M_{m}$ based on the economic point of view is $25 \%$ as mentioned earlier. The series of Oedometer tests used to evaluate the swelling pressure of the expansive soil confirms that, $M_{m}$ enhances the properties of the expansive soil leading to the formation of a new improved material. 


\subsection{The effect of micro-metakaolin on the shear strength of the expansive soil:}

Direct shear tests have been performed on the treated soil for different micro-metakaolin contents according to ASTM D3080-11 in the soaked state and according to the ECP 202-part 2 in the unsoaked state to assess the components of the shear strength in both states. Although, it is hard to assess the shear strength of bentonite in the soaked state as it requires at least 8 days to reach the final expansion ratio as stated by Elmashad (2017) and Komine \& Ogata (1994), a few tests were conducted on the expansive soil in the soaked state as indicative tests.

The results of the tests on each specimen are plotted on a graph with the shear strength on the $y$-axis and the normal stress on the x-axis as shown in Figure 12. The y-intercept of the line which fits the test results is the undrained cohesion $\left(c_{u}\right)$ and the slope of the line is the secant friction angle $(\varphi)$. As can be seen from Figure 12a for the unsoaked state condition, the cohesion $\left(c_{u}\right)$ equals $9.9 \mathrm{kN} / \mathrm{m}^{2}$ and the secant friction angle $(\varphi)$ equals 26.9 degrees. The value of the angle of internal friction is high as the expansive soil sample consists mainly of $\mathrm{SiO}_{2}$ (Quartz). Figure $12 \mathrm{~b}$ shows the results of the shear strength test in the soaked state condition where, the cohesion $\left(c_{u}\right)$ equals $21.3 \mathrm{kN} / \mathrm{m}^{2}$ and the friction angle $(\varphi)$ equals nearly 31.6 degrees. Also, the same Figure $12 \mathrm{~b}$ shows the results of the shear strength test for another two cases conducted as indicative tests. The expansive soil was allowed to swell without any additional load and after it reached its full expansion volume, it was tested to assess its shear strength components $\left(c_{u} \& j\right)$. Meanwhile, its water content was measured. This test was performed as an indicative test but the effect of adding micro-metakaolin to expansive soil was studied by applying loads according to the ECP 202-part 5. For the soaked state condition, at $W_{c}=108$ and $123 \%$, the cohesion $\left(c_{u}\right)$ reached 14.24 and $19.61 \mathrm{kN} / \mathrm{m}^{2}$, respectively and the secant friction angle $(\varphi)$ reached 6.8 and 1 degrees, respectively. These results are consistent with those results obtained by Sinha (1998) and Gleason et al. (1997).

Figures $13 \mathrm{a}$ and $13 \mathrm{~b}$ present the variation of normal stress with the shear strength for micro-metakaolin soil mixtures in the unsoaked and the soaked states, respectively. While, Figures $14 \mathrm{a}$ and $14 \mathrm{~b}$ gives the relationship between micro-metakaolin contents and shear strength at different normal stresses in both the unsoaked and the soaked states, respectively. As can be seen from Figures 13a and 14a adding $M_{m}$ up to $10 \%$, is associated with an increase of about $12.2 \%$ in the values of the shear strength of soil. However; at higher percentages, the shear strength decreases to about its initial value before the addition of $M_{m}$. While, Figures $13 \mathrm{~b}$ and $14 \mathrm{~b}$ show that $M_{m}$ enhances the expansive soil shear strength properties in the soaked state by around $13 \%$ at $25 \% M_{m}$ content.

The shear strength was studied in terms of frictional angle and cohesion of micro-metakaolin-soil mixtures for the unsoaked and soaked states. The relative angle of internal friction $\left.\left.{ }^{\left(\varphi_{m}\right.}\right)\right)$ after adding $M_{m}$ in both the unsoaked and soaked states increases with the increase in the micro-metakaolin content (where; $j_{m}$ is the angle of internal friction for the mixture and $j$ is the angle of internal friction of the untreated expansive soil). In the unsoaked state, it reaches around $117 \%$ at $10 \% M_{m}$ content. After that, 
the angle of internal friction decreases with the increase in the content until it reaches its initial value for the untreated soil. While, in the soaked state the relative angle of internal friction increases with the increase of $M_{m}$ content as it reaches around $115 \%$ at $25 \% M_{m}$. This increase in the values of the relative angle of internal friction is attributed to the friction between micro-metakaolin and the soil particles.

As for the cohesion after adding $M_{m}$ in both the unsoaked and soaked states, it is found that it decreases with the increase in the $M_{m}$ content. The decrease was found to be about $30 \%$ in the unsoaked state and about $4.5 \%$ in the soaked state at $25 \% M_{m}$ content. The addition of such material leads to agglomeration of soil particles leading to the decrease in the cohesion of soil mixtures.

It can be concluded that, adding $M_{m}$ to the expansive soil is effective in controlling the swelling pressure, however, the shear strength increased by around $12 \%$ in the unsoaked state by adding $10 \% M_{m}$ content. While for the soaked state, the shear strength improved by around $13 \%$ at $25 \% M_{m}$ content.

In the context of this study, the modulus of elasticity (Young's modulus, $E$ ) is taken as the initial tangent of the stress-strain curves, which is obtained utilizing the direct shear box. The Young's modulus of both the untreated $(E)$ and treated expansive soil $\left(E_{S}\right)$ in the unsoaked and soaked states are determined. Then, the relative Young's modulus in both states is calculated and plotted for different micro-metakaolin contents. Figure 15a shows the relative Young's modulus in the unsoaked state while, Figure 15b shows the relative Young's modulus in the soaked state for different micro-metakaolin contents. No change in Young's modulus after micro-metakaolin was added in the unsoaked state. While it can be seen that, in the case of soaked state there is a slight reduction in the relative Young's modulus after the addition of $10 \%$ micro-metakaolin. This indicates that soaked soil tends to be more plastic due to the agglomeration of micro-metakaolin within the mixture.

\section{Comparing Different Stabilization Techniques}

In order to show the beneficial effect of micro-metakaolin stabilization technique that utilizes a cheap and readily available material, a comparative evaluation of different stabilization techniques was performed. The reduction in swelling pressure $\left(S p_{r}\right)$ as defined earlier, for different additives is presented in Fig. 16. It is found that treating expansive soil with micro-metakaolin provides an overall satisfactory results compared to alternative materials used to improve the swelling characteristic, such as fly Ash (Kate, 2008), cement bypass dust (Taha et al., 2001) and lime replacement commercially known as Addicrete-P (Abdulaziz et al., 2013).

Comparatively, both the adopted techniques of micro-metakaolin and fly ash significantly decreased the swelling pressure of the expansive soils. Micro-metakaolin absorbs all the excess water entering the soil voids leading to the formation of a new mixture with less swelling ability where the voids between soil particles are reduced at same time. Generally, the addition of such material leads to agglomeration of soil particles, which seems to decrease the swelling behavior of the expansive soil. Whereas, the stabilization by cement bypass dust (CBPD) as presented by Taha et al. (2001), reported a slight increase in the 
swelling pressure of soil followed by a relatively lower swelling behavior. The initial increase in swelling pressure was attributed to the presence of lime in the CBPD. When more CBPD content was added, silica, aluminia and calcium oxide were released, which enhance the swelling behavior of soil.

While, the use of chemical additives such as Addicrete-P (Abdulaziz et al., 2013) showed significant effect in reducing the swelling pressure of expansive soils at low percentages. Meanwhile, from the economic point of view this material is considered to be relatively expensive compared to micrometakaolin.

Finally, based on the above results, the proposed approach of improving the engineering characteristics of expansive soils using micro-metakaolin is found to be effective and can lead to a significant decrease in the overall swelling behavior of the treated soil.

\section{Conclusions}

An extensive laboratory testing program was carried out to investigate the effect of using micrometakaolin to improve the characteristics of highly expansive soils. The chemical and physical characteristics of expansive soil minerals is investigated using two techniques: (1) measuring the macroscopic properties as water content and density; and (2) measuring the microscopic properties such as interlayer spacing and the specific interactions between soil layers and any additive used to improve the soil. In this study, both of these techniques allowed for a better understanding of the soil response before and after treatment.

Based on this experimental study, the following conclusions can be made:

- The performed microscopic analysis showed that a new improved material with lower swelling potential will form as a result of adding $M_{m}$ to expansive soil.

- Soil treated with $M_{m}$ is found to have higher plastic limit, lower liquid limit and plasticity index due to low water absorption of water. For example, at $25 \% M_{m}$ content, plasticity index was found to decrease by about $43 \%$.

- Expansive soil treated with $M_{m}$ showed significantly lower swelling potential and swelling pressure as compared to untreated soil. Adding $25 \% M_{m}$ to the soil, both the swelling pressure and the free swell index decreased by $33 \%$ and $54 \%$, respectively.

- When $15 \% M_{m}$ is added to the expansive soil, the maximum dry unit weight slightly increased by about $7 \%$.

- The measured changes in shear strength of the treated soil was found to be relatively small. Adding $10 \% M_{m}$ to the expansive soil resulted in an increase in shear strength by about $12 \%$ in the unsoaked state with negligible change in the soaked state.

- Finally, based on the results of this study, it can be concluded that micro-metakaolin may be used as an economic and efficient stabilizer to treat expansive soils. 


\section{Declarations}

\section{Declaration of interests}

The authors declare that they have no known competing financial interests or personal relationships that could have appeared to influence the work reported in this paper.

\section{Authors' contributions}

Mohamed A. Sakr: Principal investigator (P. I.), Work coordinator, Data Analysis, Paper Writaing Curation, and final review. Waseim R. Azzam: Data curation and analysis, Visualization, Reviewing and Editing. Mohamed A. Meguid: Reviewing and Editing. Hebatalla A. Ghoneim (Corresponding Author): CoPrincipal investigator (Co-P. I.), Conceptualization, Methodology, Visualization, Investigation, Editing and writing.

\section{References}

Abdel Gawwad HA, Abd El-Aleem S, Faried AS. Influence of nano-silica and -metakaolin on the hydration characteristics and microstructure of air-cooled slag-blended cement mortar. Geosystem Eng 2017;20:276-85. https://doi.org/10.1080/12269328.2017.1323678.

Abdulaziz ESM, Taha YK, Kenawi MA, Kamel AO. Treatment of expansive soil with chemical additives. Journal of Engineering Sciences, Assuit University, Faculty of Engineering 2013;41:1765-77.

Ahmed TA, Kamel AO. Improvement of Swelling Soil under Traffic Areas Using Dust Shield Polymer 2013;3:368-71

Alzaidy MNJ. Experimental study for stabilizing clayey soil with eggshell powder and plastic wastes. IOP Conf Ser Mater Sci Eng 2019;518:1-13. https://doi.org/10.1088/1757-899X/518/2/022008.

Alzubaidi RM, Alrawi K, Alfalahi A. Comprehensive approach for swelling soil remedies. Geomate 2016;11:2611-9.

ASTM International. Standard test methods for laboratory compaction characteristics of soil using modified effort 2003 (D1557). https://doi.org/10.1520/D1557-09.1

ASTM International. Standard test method for direct shear test of soils under consolidated drained conditions 2011 (D3080-11). https://doi.org/10.1520/D3080-04.2

ASTM International. Standard test method for liquid limit, plastic limit and plasticity index of soils 2005 (ASTM D 4318-10). https://doi.org/10.1520/D4318-05.1.5.

ASTM International. Standard test methods for one-dimensional swell or settlement potential of cohesive soils 2013 (D4546-08). https://doi.org/10.1520/D4546-08.2 
Ayadat T, Belouahri B. Influence du coefficient d'uniformité sur l'amplitude etle taux de l'affaissement des sols. Revue Française de Géotechnique in French (Canada)1996;77.

Azzam WR. Reduction of the shrinkage-swelling potential with polymer nanocomposite stabilization. J Appl Polym Sci 2012;123:299-306. https://doi.org/10.1002/app.33642.

Bayang F, Defence N, Engbonye J, Nigerian S, Academy D. Laboratory assessment of metakaolin effect on the volumetric shrinkage of black cotton soil for flexible pavement construction. Civil and environmental research 2017; 9:16-29.

Benkadja R, Belouahri B. Influence of oil on the magnitude and rate of collapsible soils. J Civ Eng Res Pract 2010;7:1-12. https://doi.org/10.4314/jcerp.v7i1.56482.

Cheng Y, Huang X. Effect of mineral additives on the behavior of an expansive soil for use in highway subgrade soils. Appl Sci 2018;9:1-14. https://doi.org/10.3390/app9010030.

De Azeredo Melo LG, Pereira RA, Pires EFC, Darwish FAl, Da Silva FJ. Physicochemical characterization of pulverized phyllite rock for geopolymer resin synthesis. Mater Res 2017;20:23643. https://doi.org/10.1590/1980-5373-MR-2016-0968.

Elmashad ME. Effect of chemical additives on consistency, infiltration rate and swelling characteristics of bentonite. Water Sci 2017;31:177-188 https://doi.org/10.1016/j.wsj.2017.07.001.

Forouzan AJ. Prediction of swelling behavior of expansive soils using modified free swell index, methylene blue and swell oedometer tests. Dissertation Technical University of Middle East, Turkey 2016

Gleason MH, Daniel DE, Eykholt GR. Calcium and sodium bentonite for hydraulic containment applications. J Geotech Eng 1997;123:438-45. https://doi.org/10.1061/(ASCE)10900241(1997)123:5(438).

Gupta C, Sharma RK. Influence of marble dust, fly ash and beas sand on subgrade characteristics of expansive soil. J Mech Civ Eng 2014;13:13-8.

Hassan AA. Effect of high temperatures on a mixture of alkali-activated metakaolin pastes and quartz powder. The $8^{\text {th }}$ International Conference on Nanotechnology for green and sustainable constructions (NTC), Sharm El- Sheikh, Egypt 2016.

HBRC. Egyptian Code of practice for soil mechanics, design and construction of foundations (ECP 202part 5: Foundations on problematic soils) 2006.

HBRC. Egyptian Code of practice for soil mechanics, design and construction of foundations (ECP 202part 2: laboratory tests) 2006. 
Husain A, Abad KR, Ahmad khan N. Swelling properties of improved expansive soil by rice husk ash (RHA) and silica fume (SF). International Archive of Applied Sciences and Technology 2014;5:22-29

Ikeagwuani CC, Nwonu DC. Emerging trends in expansive soil stabilisation: A review. J Rock Mech Geotech Eng 2019;11:423-40. https://doi.org/10.1016/j.jrmge.2018.08.013.

Jagwani D, Jaiswal A. Expansive soil stabilization by cinder of coconut husk. SSRN Electron J 2019;6:19. https://doi.org/10.2139/ssrn.3353634.

Kate JM. Strength and volume change behavior of expansive soils treated with fly ash. Innov Grouting Soil Improv 2008;136:1-15. https://doi.org/10.1061/40783(162)19.

Komine $\mathrm{H}$, Ogata N. Experimental study on swelling characteristics of compacted bentonite. Canadian Geotechnical Journal 1994;31:478-490

Mesfun RT, Quezon ET, Geremew A. Experimental study of stabilized expansive soil using pumice mixed with lime for subgrade road construction. Int J Res 2019;7:118-

24. https://doi.org/10.29121/granthaalayah.v7.i7.2019.736.

Morsy MS. Characteristics of composite cement mortar containing nano metakaolin and silica flour. The $7^{\text {th }}$ International Conference on Nanotechnology for green and sustainable constructions (NTC), Sharm El-Sheikh, Egypt 2015.

Naeini SA, Naderinia B, Izadi E. Unconfined compressive strength of clayey soils stabilized with waterborne polymer. KSCE J Civ Eng 2012;16:943-9. https://doi.org/10.1007/s12205-012-1388-9.

Nagar AM, Abu zeid MM. Production of eco friendly zero portland cement from slag and metakaolin materials. The $10^{\text {th }}$ International Conference on Nanotechnology for green and sustainable constructions (NTC), Hurgada, Egypt 2018.

Naseem A, Mumtaz W, Fazal-e-Jalal, De Backer H. Stabilization of expansive soil using tire rubber powder and cement kiln dust. Soil Mech Found Eng 2019;56:54-8. https://doi.org/10.1007/s11204-019-09569-8.

Nazir AK. Stabilization of collapsible soil with engine oil. International review of civil engineering 2012;3:487-492.

Rabah AK. Engineering properties of fiber reinforced collapsible soil. Dissertation University of Tanta, Egypt 2014.

Sakr MA, Azzam WR, Meguid MA, Ghoneim HA. On the use of nanoclay to improve the swelling properties of expansive soils. The $12^{\text {th }}$ International Conference on Nanotechnology for green and sustainable constructions (NTC), Egypt 2021; on CD 
Sakr MA, Azzam WR, Meguid MA, Ghoneim HA. Utilization of micro-metakaolin to improve the swelling potential of expansive soils. The $13^{\text {th }}$ International Geological Conference (SSG), Jeddah SA 2020; on CD.

Sakr MA, Sawaf MA, Nazir AK, Rabah AK. Behavior of collapsible soils stabilized with fibers. Eighth Alexandria International Conferences on Structural and Geotechnical Engineering (AICSGE 8) Egypt 2014:GT 119-129.

Sankar VS, Raj PDA, Raman SJ. Stabilization of expansive soil by using agricultural waste. Int J Eng Adv Technol 2019;8:154-7.

Siddique R, and lqbal Khan M. Metakaolin in: Supplementary Cementing Materials. Berlin, Heidelberg: Springer Berlin Heidelberg 2011;37. https://doi.org/10.1007/978-3-642-17866-5_4.

Sinha AN. Shear strength of bentonite-kaolinite mix in GCLs. Geosynthetica International 1998;4:889-896.

Taha MR, Taha OME. Influence of nano-material on the expansive and shrinkage soil behavior. J Nanoparticle Res 2012;14:1-13. https://doi.org/10.1007/s11051-012-1190-0.

Taha R, Al-Rawas A, Al-Harthy A, Al-Siyabi H. Use of cement by-pass dust in soil stabilization. Eng J Univ Qatar 2001;14:61-76

Thanappan S, Tesfaye M, Tariku S, Abdulahi T, Abebe S. Stabilization on expansive soil for civil engineering projects. Int J Sci Technol Res 2020;9:5714-8.

Zeedan SR, El Shimy E. Alkali silicate activation and characterization of geopolymers of slag/ metakaoline composite. The $4^{\text {th }}$ International Conference on Nanotechnology for green and sustainable constructions (NTC), Cairo, Egypt 2012.

Zhang F, Zhang L, Hong W. Stabilization of expansive soil with polyvinyl alcohol and potassium carbonate. Adv Civ Eng 2019;2019:1-11. https://doi.org/10.1155/2019/7032087.

\section{Figures}



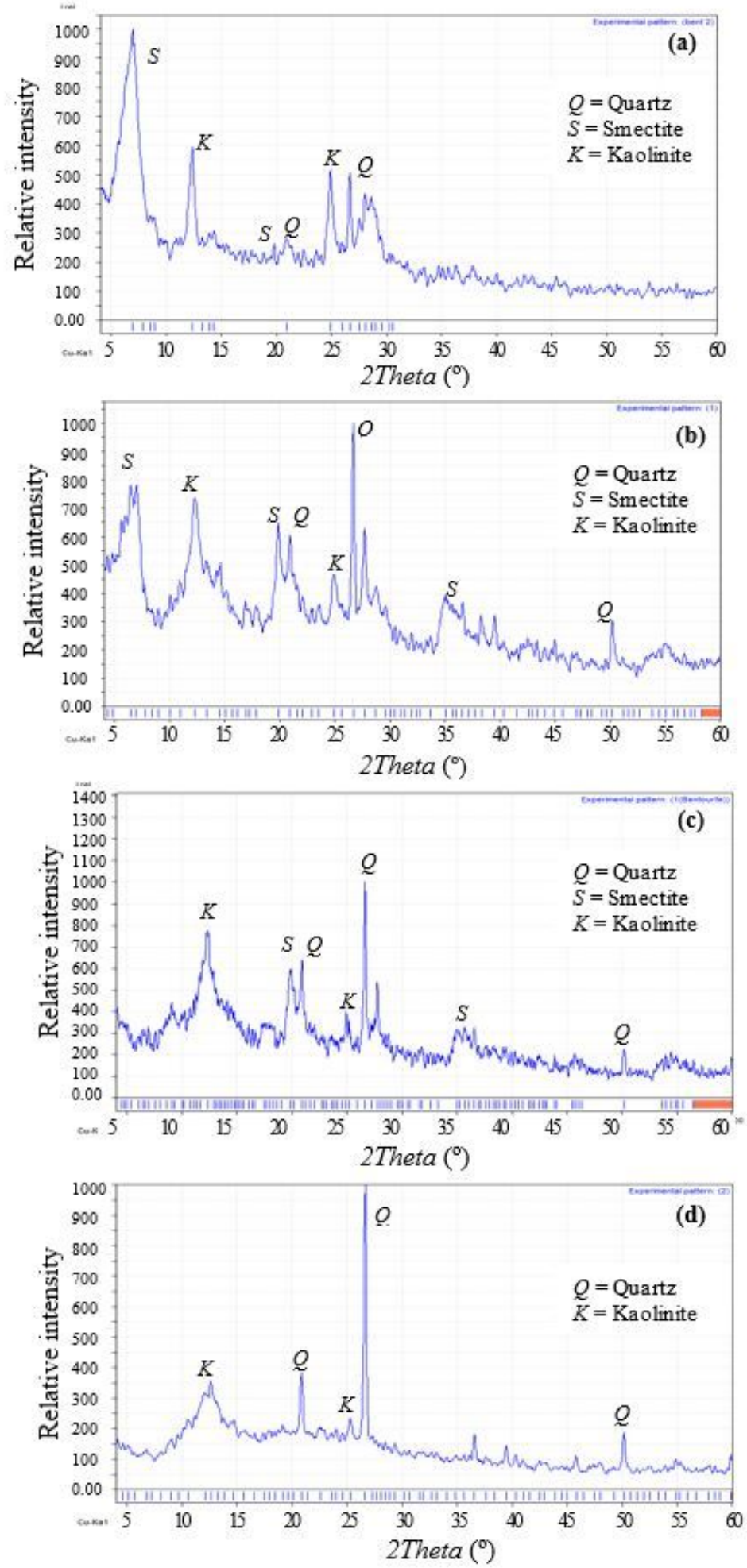

\section{Figure 1}

XRD patterns at different magnification power: (a) wet bentonite; (b) dry bentonite; (c) oven dried bentonite; (d) micro-metakaolin material 

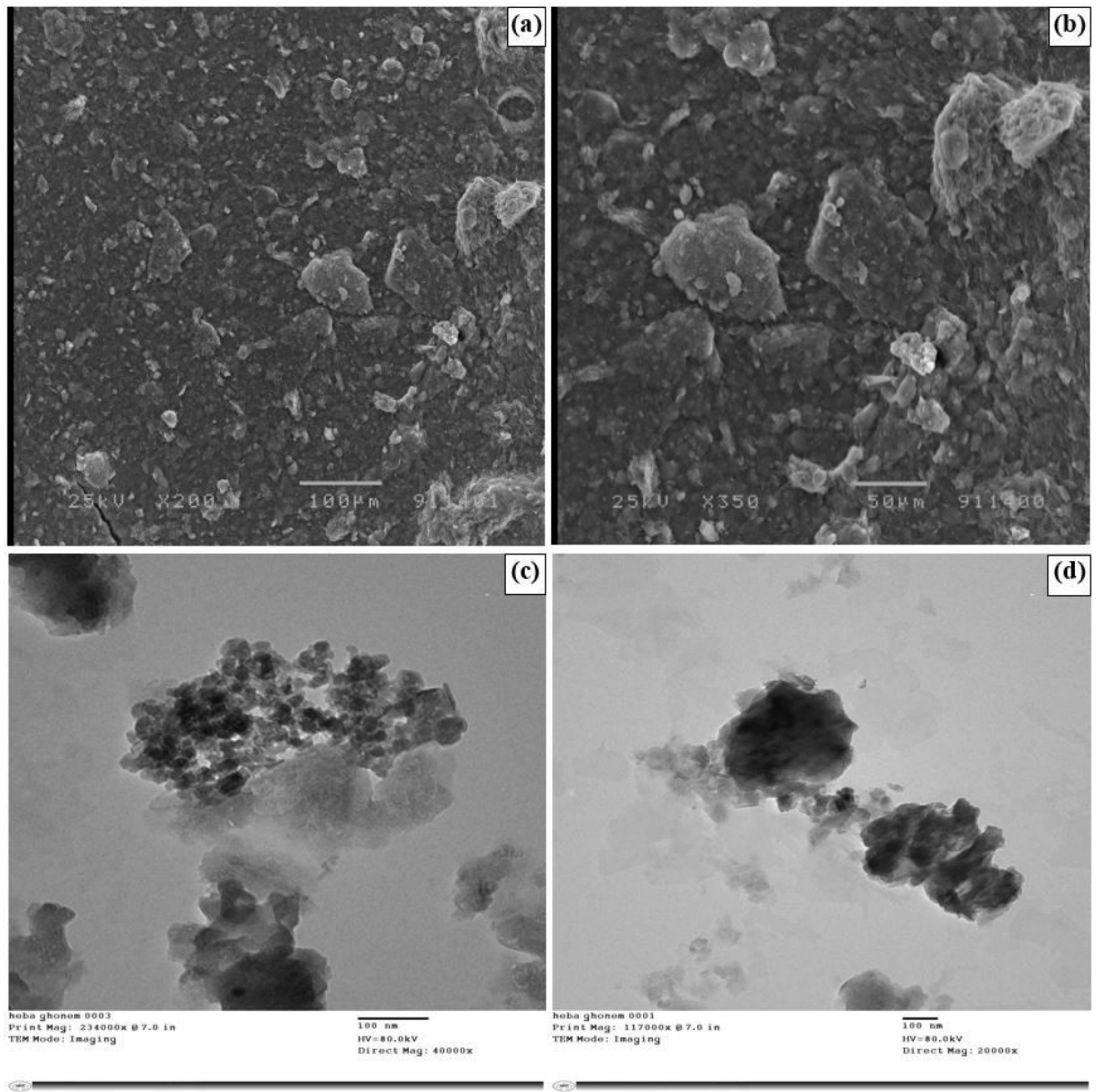

\section{Figure 2}

(a) SEM of the bentonite at 200' and particle size $100 \mu m$; (b) SEM of the bentonite at 350' and particle size $50 \mu \mathrm{m}$; (c) TEM of the bentonite at 40000' and particle size $100 \mathrm{~nm}$; (d) TEM of the bentonite at 20000' and particle size $100 \mathrm{~nm}$ 


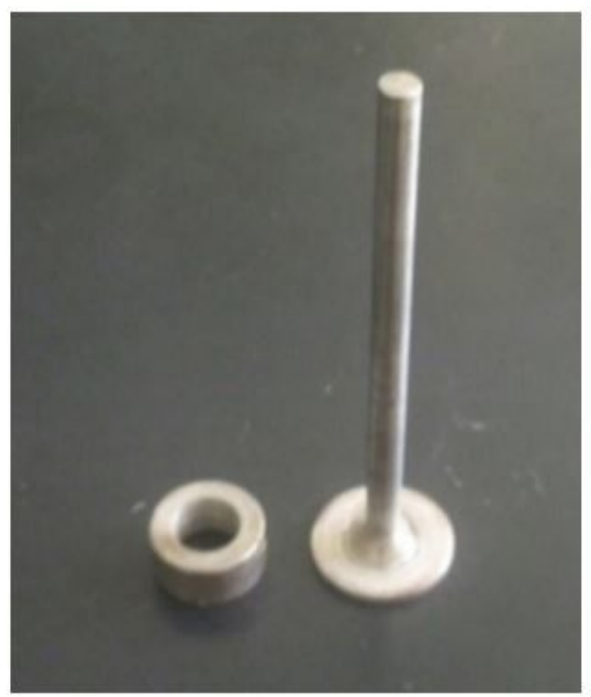

(a) Tool of compaction

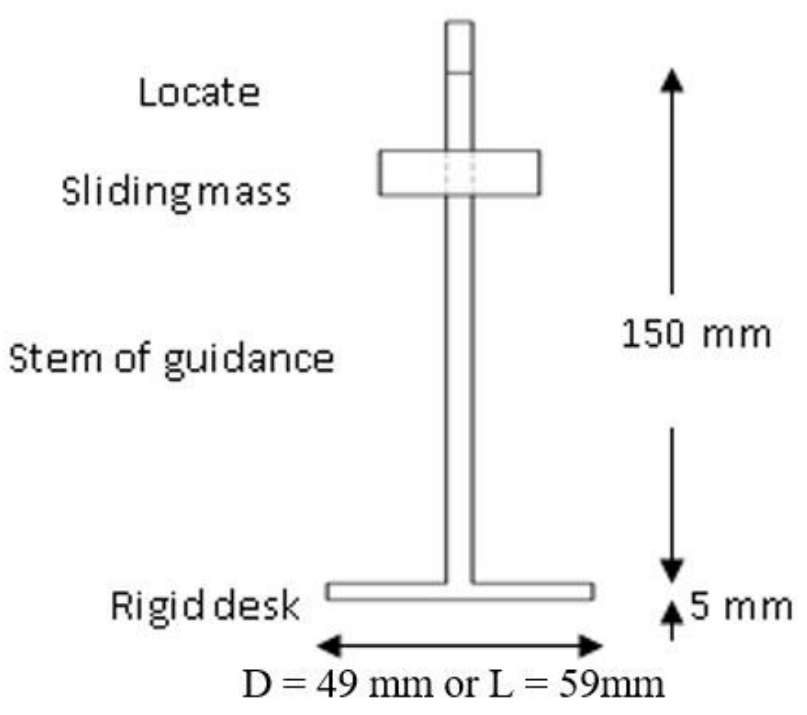

(b) Dimensions of the compaction tool

\section{Figure 3}

The compaction tool used for sample preparation (Sakr et al., 2014; Ayadat and Belouahri, 1996; Rabah, 2014) 


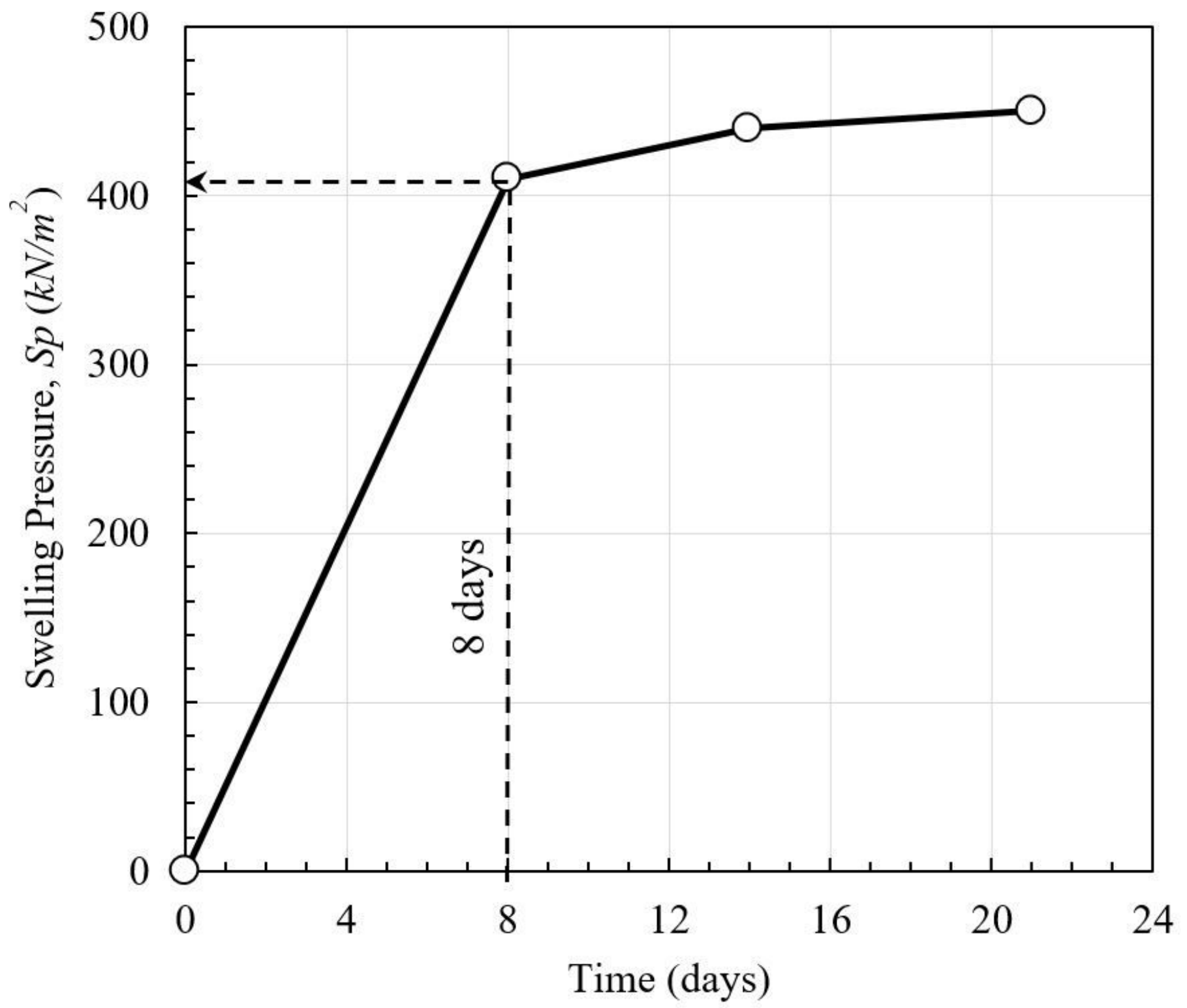

Figure 4

Swelling pressure for the raw material versus time 


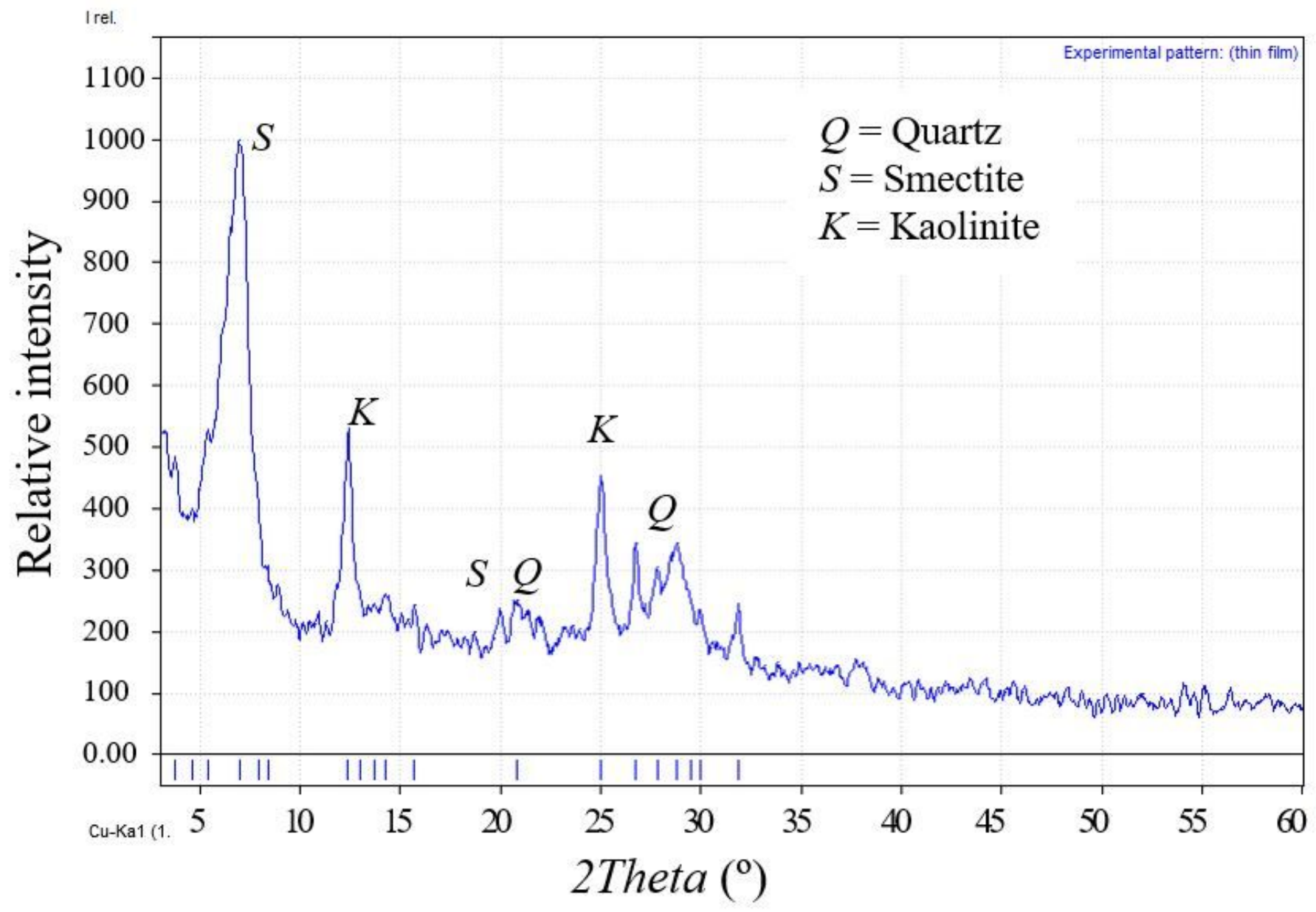

Figure 5

XRD pattern of the expansive soil treated with $25 \%$ micro-metakaolin by dry weight 

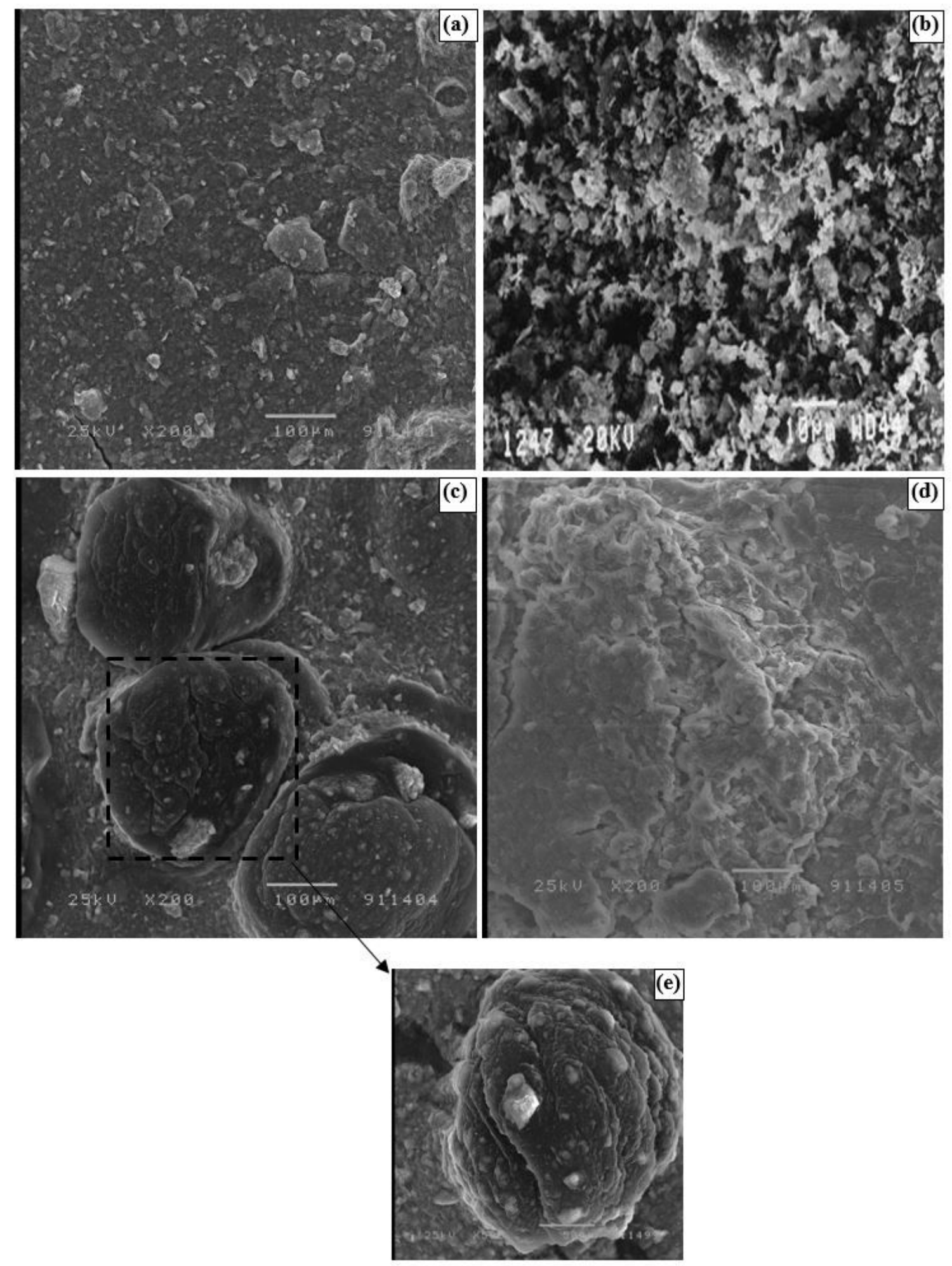

\section{Figure 6}

SEM images showing the effect of adding micro-metakaolin to the expansive soil:

(a) no additives (current study); (b) results reported by others (Siddique and lqbal, 2011) for $M_{m}$ material;

(c) $10 \% M_{m}$ treated soil (current study); (d) $25 \% M_{m}$ treated soil (current study); (e) Kaolinite booklet (current study) 

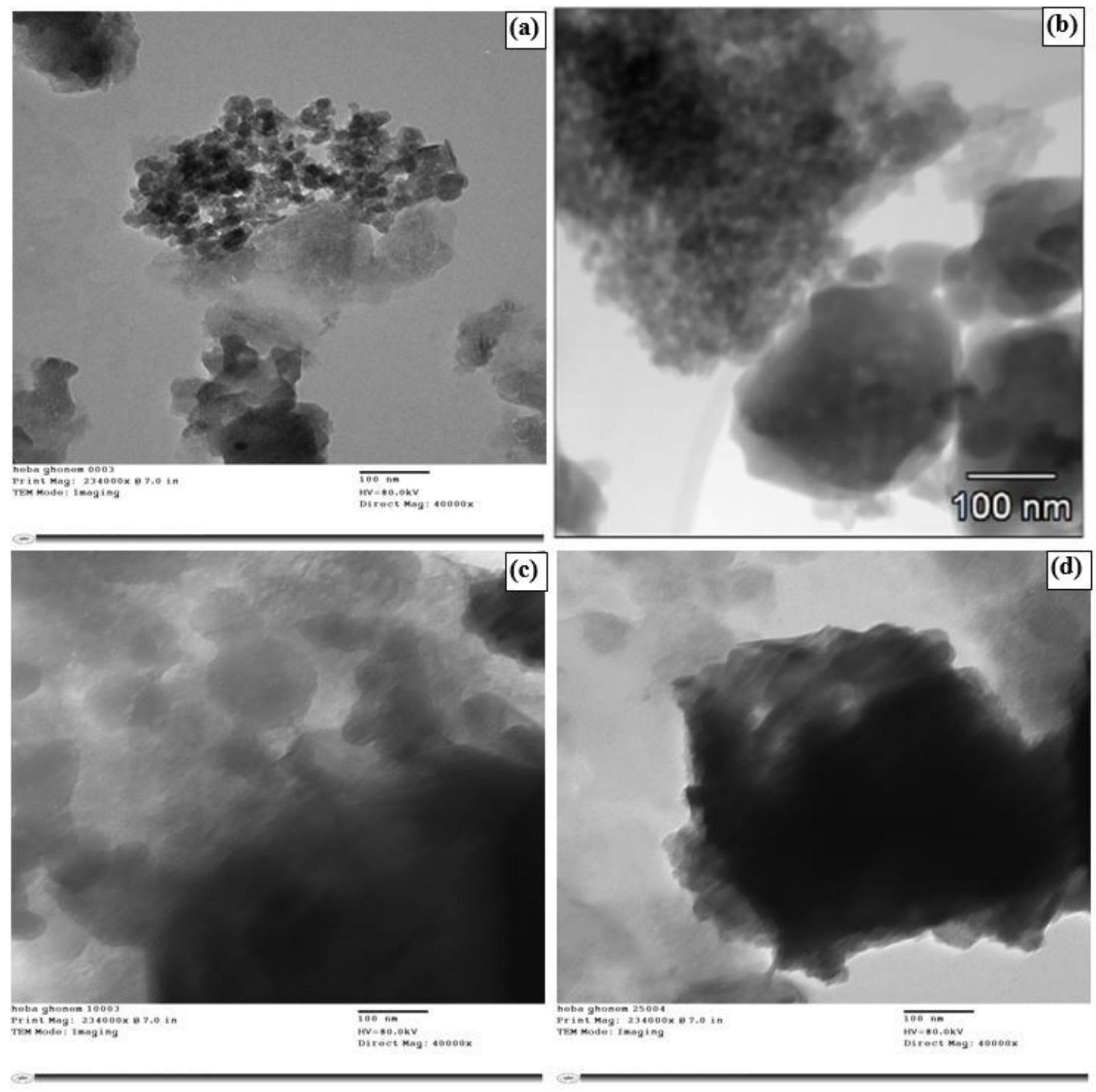

\section{Figure 7}

TEM images showing the effect of adding $M_{m}$ to the expansive soil:

(a) no additives (current study); (b) results reported by others (De Azeredo Melo et al., 2017) for $M_{m}$ material; (c) $10 \% M_{m}$ treated soil (current study); (d) 25\% $M_{m}$ treated soil (current study). 


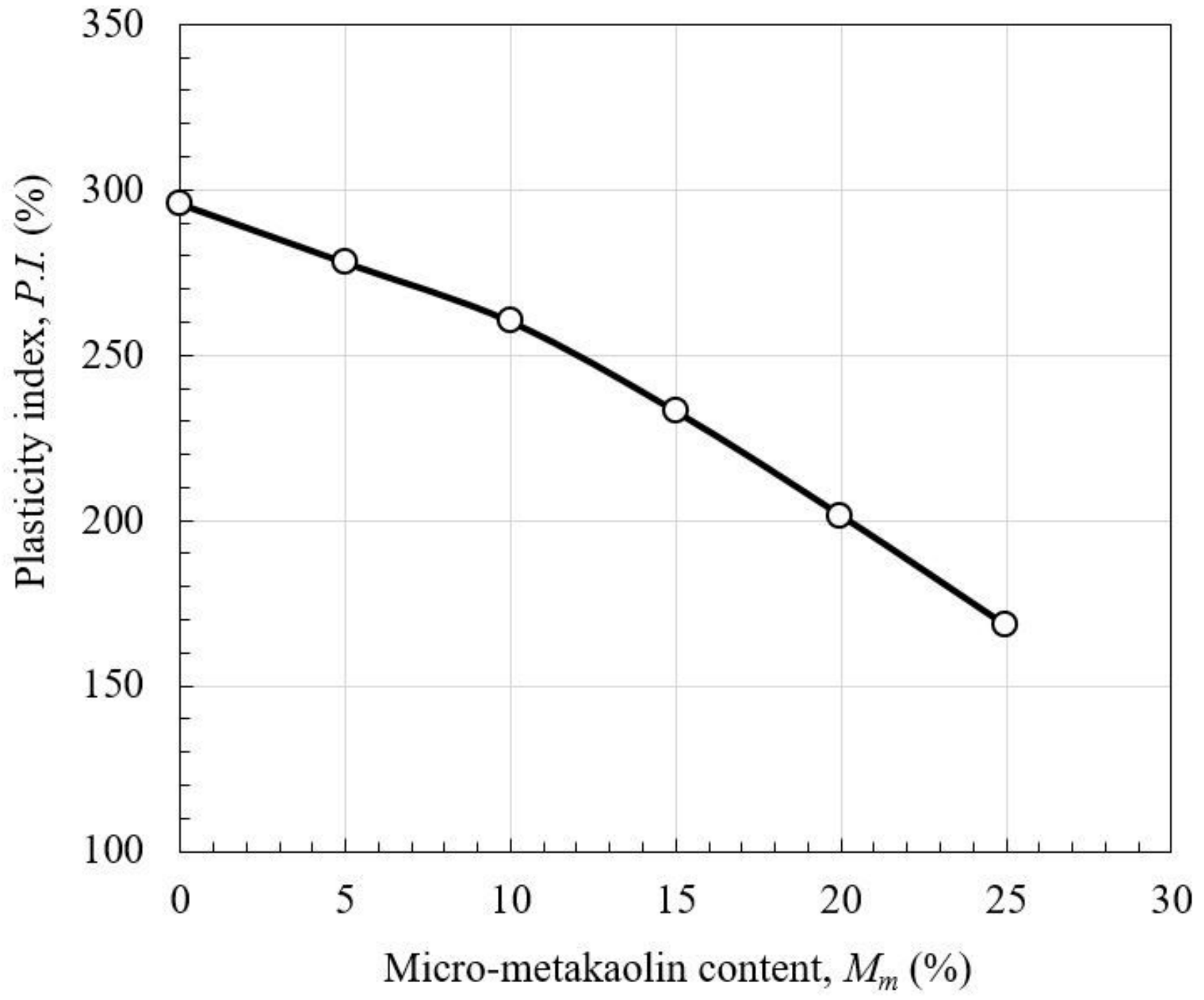

Figure 8

The effect of adding micro-metakaolin on the plasticity index of the expansive soil 


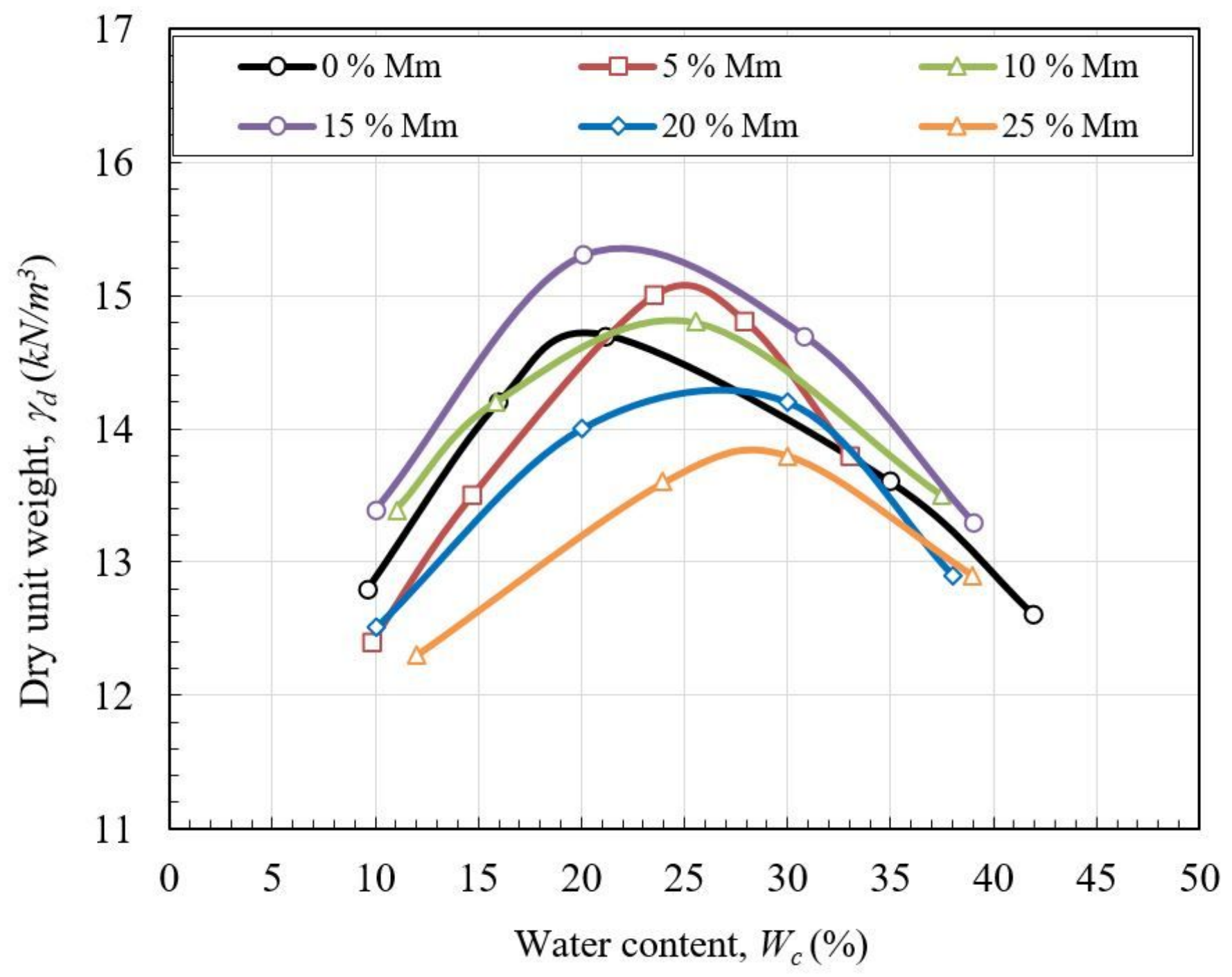

Figure 9

The relationship between the dry unit weight and the water content for the expansive soil samples after adding the micro-metakaolin 


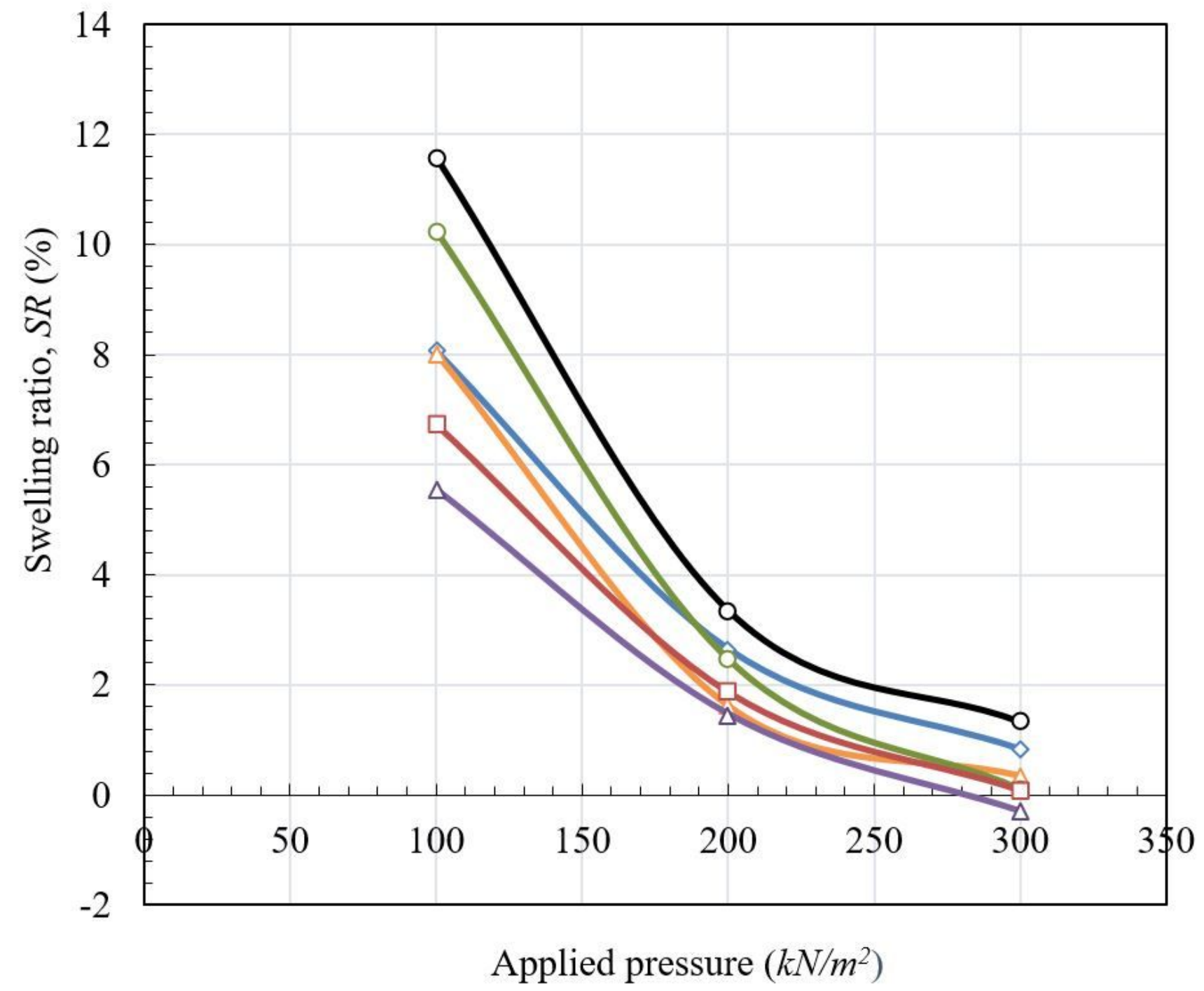

\section{$\rightarrow 0 \%$ Micro metakaolin $\quad \longrightarrow 5 \%$ Micro metakaolin $\quad-10 \%$ Micro metakaolin \\ $-0-15 \%$ Micro metakaolin $\quad-\square-20 \%$ Micro metakaolin $\quad-\quad-25 \%$ Micro metakaolin}

Figure 10

Relationship between the swelling ratio and the applied loads in the Oedometer cell 

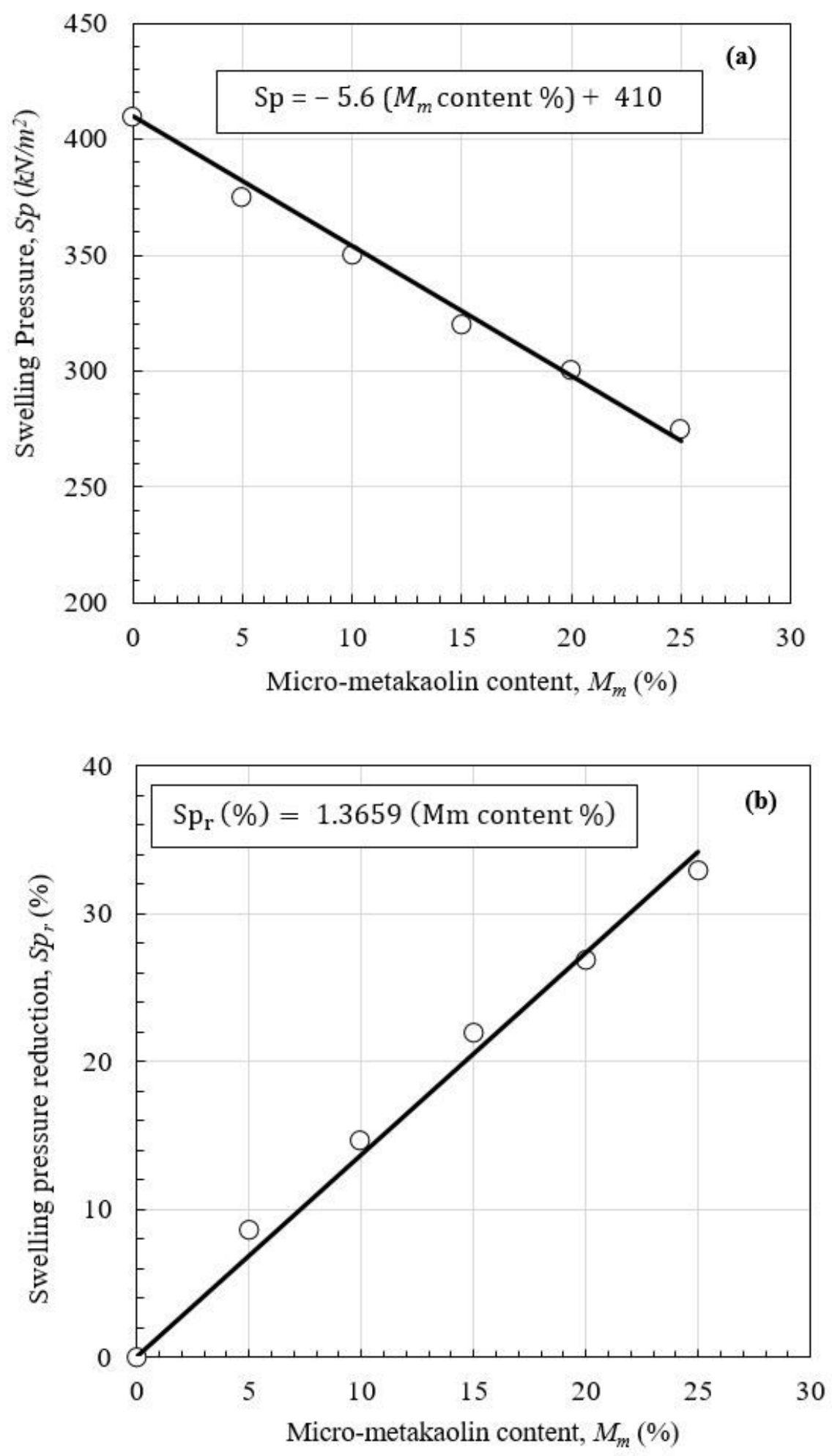

Figure 11

Swelling behavior of soil after micro-metakaolin addition: (a) Swelling pressure; (b) Reduction in the swelling pressure 

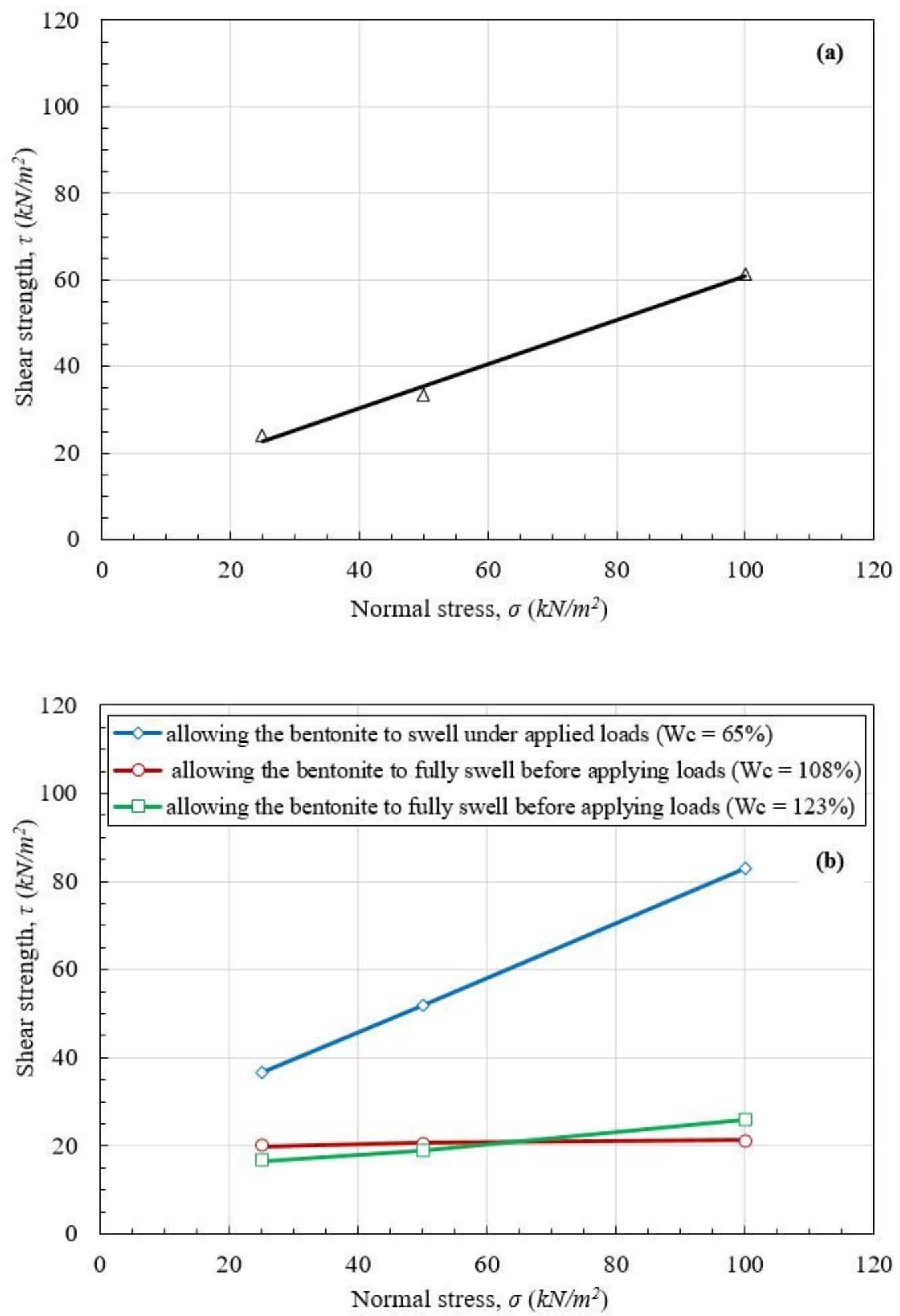

Figure 12

Variation of normal stress with shear strength for untreated soil sample in:

(a) the unsoaked state; (b) the soaked state 

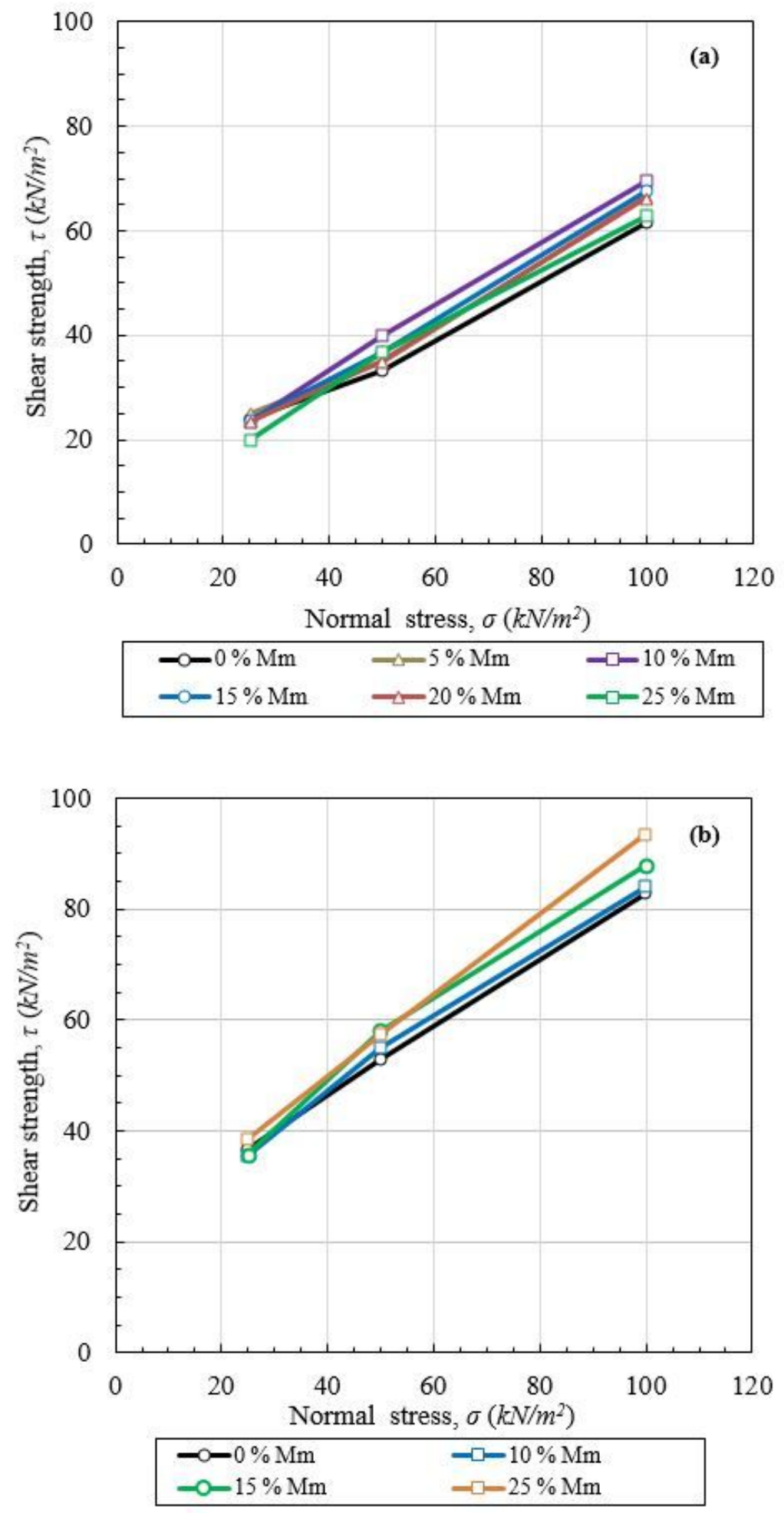

Figure 13

Normal stress vs. shear strength relationships for micro-metakaolin - soil mixtures in: (a) the unsoaked state; (b) the soaked state 

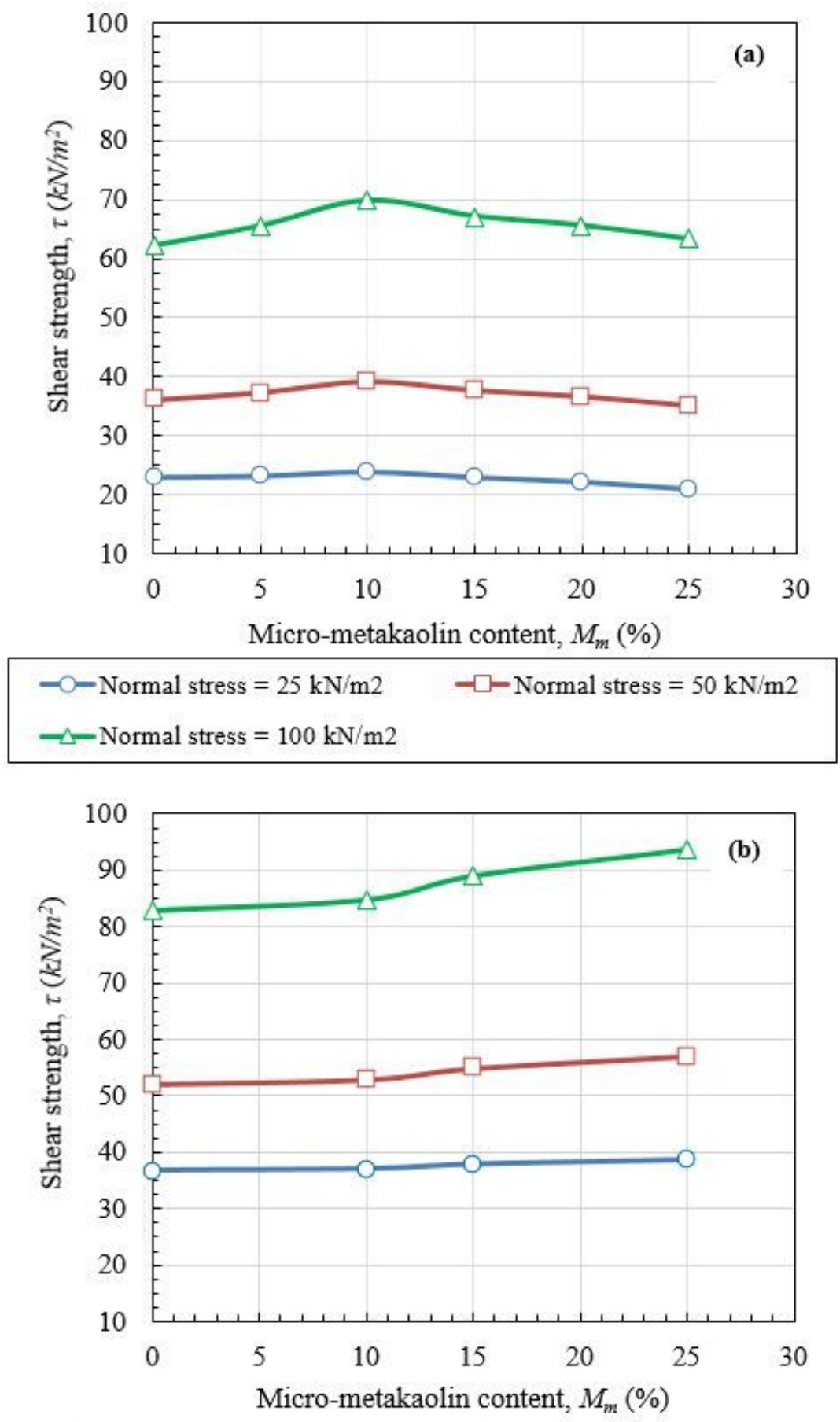

\footnotetext{
$\multimap-$ Normal stress $=25 \mathrm{kN} / \mathrm{m} 2 \quad-\square-$ Normal stress $=50 \mathrm{kN} / \mathrm{m} 2$ $\neg$ Normal stress $=100 \mathrm{kN} / \mathrm{m} 2$
}

\section{Figure 14}

Relationship between $M_{m}$ and shear strength at different normal stresses in:

(a) the unsoaked state; (b) the soaked state 

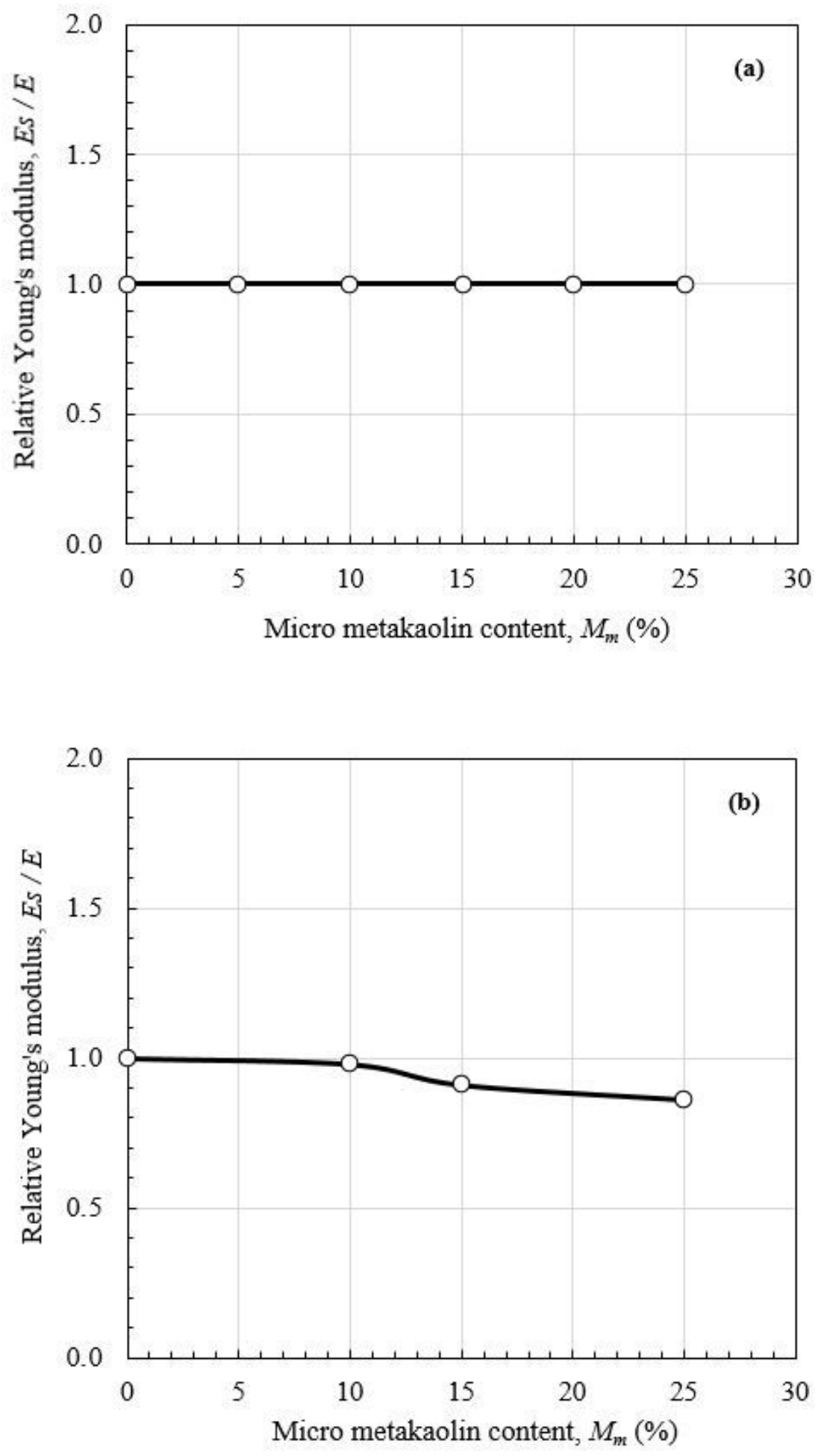

Figure 15

The effect of adding micro-metakaolin on Young's modulus:

(a) in the unsoaked state; (b) in the soaked state 


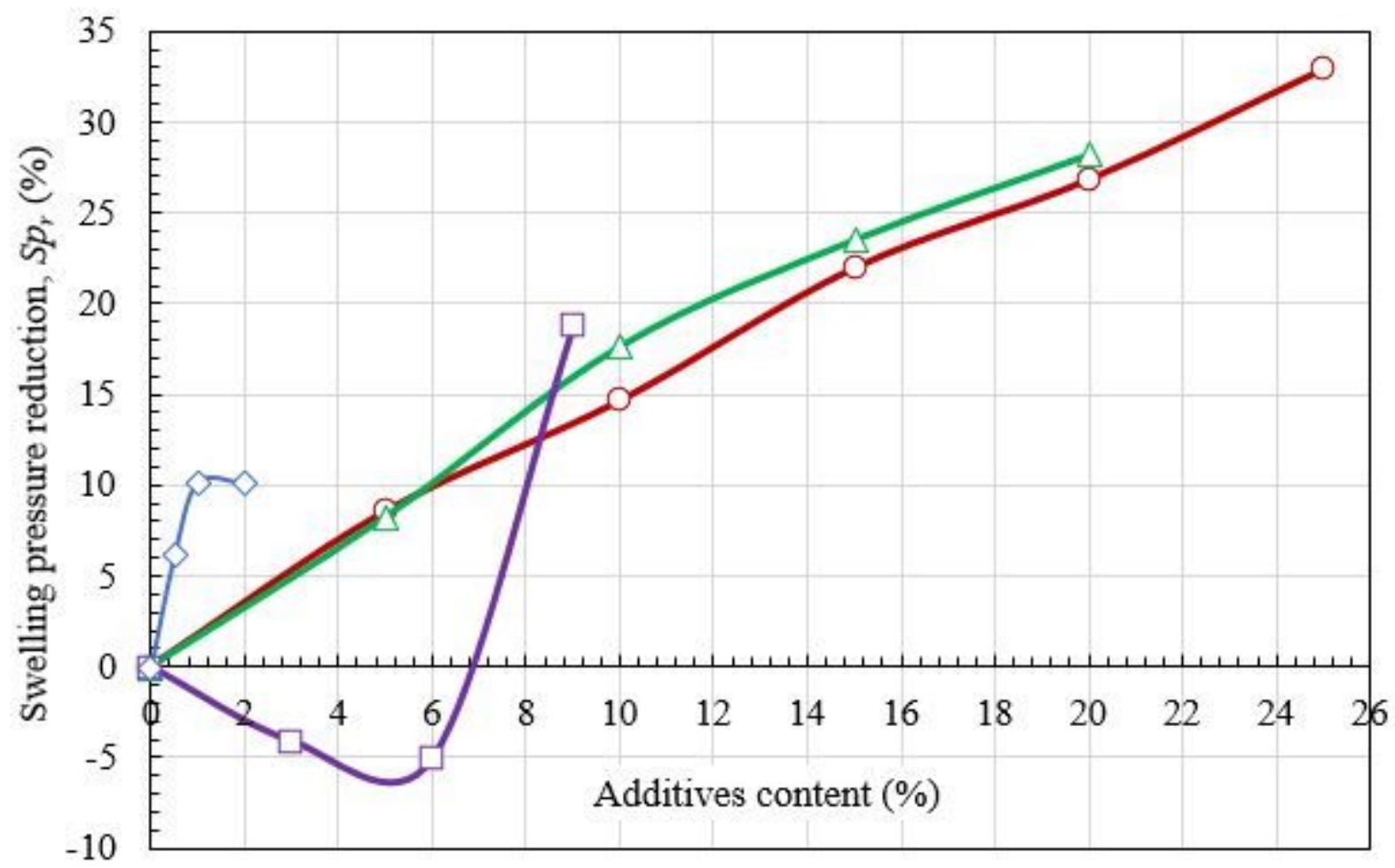

$\longrightarrow$ Micro metakaolin content (current study) $\quad \longrightarrow$ Fly ash content (Kate, 2008)

$\rightarrow \square$ Cement bypass dust content (Taha et al., 2001) $\longrightarrow$-Addicrerte P content (Abdulaziz et al., 2013)

\section{Figure 16}

Comparing the effects of different additives on the swelling pressure 